\title{
An investigation into the freshwater variability in West Africa during $1979-2010$
}

\author{
S.A. Andam-Akorful ${ }^{a}$, V.G. Ferreira ${ }^{\text {b,* }}$, C.E. Ndehedehe ${ }^{\mathrm{c}}$, J.A. Quaye-Ballard $^{\mathrm{a}}$ \\ ${ }^{a}$ Dept. of Geomatic Engineering, Kwame Nkrumah University of Science and Technology, Kumasi, Ghana \\ ${ }^{b}$ School of Earth Sciences and Engineering, Hohai University, Nanjing, China \\ ${ }^{c}$ Western Australian Centre for Geodesy and the Institute for Geoscience Research, Curtin University, Perth, Australia
}

\begin{abstract}
After the frequent and long drought episodes of the 1980s, a plethora of case studies have shown that West Africa remains a hot spot in the continent where despite its numerous water resources, extreme rainfall variability remains a profound challenge to the availability of freshwater for agriculture and ecosystem services. In this paper, we assess the recent flux in water availability over West Africa by investigating variations in net-precipitation (i.e., the maximum available freshwater flux) using wavelet analysis. Netprecipitation was obtained as a residual of the atmospheric water balance, and its variability compared to precipitation, temperature, evaporation, soil moisture and normalized difference vegetation index using wavelet power transforms and coherence analysis. Results from the study indicate that the variance in water flux over the region has been progressively reducing, suggesting a relative reduction in extreme hydrological conditions. Also, the wavelet coherence analysis revealed that the observed decreasing rate of available freshwater is highly coupled to a low frequency modulating El-Niño activity that induced lower changes in rainfall variance, as well as higher evaporation variance. Spatial trends in the annualscaled average wavelet power indicated that the south-western parts of the region experienced the most reduction in rainfall flux. The highest deficit in net-precipitation flux was found in the dry sub-humid climatic zone, which is drained by major regional rivers, including the Niger and Volta. Considering the long-term variability in freshwater (i.e., from 1979 to 2010), we found the 1980s to be the driest decade and the 1990s being its recovery period, while the 2000s proved to be a considerably dry decade, suggesting a strong multi-decadal variability.
\end{abstract}

Keywords: Freshwater, Net-precipitation, Rainfall, Wavelet transforms, West Africa 


\section{Introduction}

In Africa, deficits in inter-annual changes in precipitation, widespread decline in vegetation greenness, and droughts (see, e.g., Zhou et al., 2014; Shiferaw et al., 2014) are relevant indicators of climate change that contribute significantly to famine and food insecurity in the region. West Africa (WA) for instance, remains a hot spot in the continent where despite its numerous water resources (e.g., Conway et al., 2009), extreme rainfall variability remains a profound challenge to the availability of freshwater for agriculture and ecosystem functioning. Consequently, the region sometimes suffers significant socio-economic losses due to its dependence on rain-fed agriculture (e.g., Shiferaw et al., 2014).

The persistent drought episodes of the late 1960s and early 1980s, which resulted in considerable impacts on water resources, food security, and livelihood, triggered numerous scientific discourse on the hydrology and climate of the region (see, e.g., Mahé and Olivry, 1999; Nicholson et al., 2000; Conway et al., 2009; Lebel and Ali, 2009; Ndehedehe et al., 2016a; Nicholson, 2013, and the references therein). While some studies have reported that rainfall amounts over WA have shown some degree of recovery as observed in the Sahel (e.g., Nicholson, 2005; Lebel and Ali, 2009), the question on the state of general moisture conditions remains unclear (cf., Nicholson, 2013). For instance, Mahé and Paturel (2009) reported that although the Sahelian rainfall amounts increased towards the late 1990s, mean annual rainfall remains well below the amounts in the pre-1970s-era. They further noted that the increase in temperature over WA during the end of the 20th century induced an increase in evaporation, and may lead to reduction in freshwater yields. Moreover, conflicting behaviour in rainfall and runoff exist in much of the region (e.g., Conway et al., 2009) while despite the recent increase in rainfall amounts in the Sahel, dry conditions persists (e.g., Descroix et al., 2009). These and other specific case studies (see, e.g., Kaspersen et al., 2011; Anyamba and Tucker, 2005; Ndehedehe et al., 2016b) in the region suggest complex eco-hydrological systems.

A plethora of case studies have reported that both climate and anthropogenic factors contribute considerably to freshwater variability in WA (e.g., Wittig et al., 2007; Roudier et al., 2014). For instance, some region-specific studies (see, e.g., Amogu et al., 2010; Descroix et al., 2009; Mahé et al., 2005) have reported that despite the reduction of rainfall rates, runoff in some sub-basins within the Niger and Volta basins have been increasing since the 1970s, a phenomenon partly attributed to human-induced impacts (e.g., land cover change). Further, Huber et al. (2011) reported inconsistent trends in Normalized Difference Vegetation Index (NDVI) and soil moisture in the African Sahel. Although they did not link it to any human influence, the preponderance of evidence from related studies, mostly those that have examined rainfall as a driver of vegetation dynamics (see, e.g., Herrmann et al., 2005; Anyamba and Tucker, 2005; Kaspersen et al., 2011), suggest the impacts of human activities and large scale climatic influence in the region. This lack of clarity in water availability and how it drives the ecosystem 
necessitates a further investigation to provide a more general perspective of recent variability in available freshwater over the region, at least in the long term. Analyzing freshwater variability in WA, however, is hampered by the fact that the region is data deficient (e.g., Conway et al., 2009; Oyebande, 2001) due to the required hydro-climatic information not being readily available. This makes it difficult to provide a more reliable account of the state of freshwater in WA.

Despite the problem of limited hydro-climatic data, various studies have attempted to analyze and explain the variability of available freshwater in the context of runoffs, rainfall patterns, and vegetation dynamics by combining available in-situ and satellite data (see, e.g., Conway et al., 2009; Descroix et al., 2009; Roudier et al., 2014; Herrmann et al., 2005; Anyamba and Tucker, 2005; Kaspersen et al., 2011). Nonetheless, most of these studies were region-specific focusing on the impacts of climate variability on vegetation production (see, e.g., Herrmann et al., 2005; Kaspersen et al., 2011), while others analyzed the uncertainties in water budget quantities derived from reanalysis and model data (see, e.g., Meynadier et al., 2010). Also, the African Monsoon Multidisciplinary Analysis (AMMA) project (e.g., Lebel et al., 2009; Boone et al., 2009) has made some progress in the region, with some observational networks now available in Niger, Mali, and Benin. In addition to the AMMA project, significant efforts on water resources development in the region include the synergy between the German research program on the global water cycle (GLOWA) and the Integratives Management-Projekt für einen Effizienten und Tragfähigen Umgang mit Süßwasser in West Afrika (IMPETUS) initiative (Speth and Fink, 2010, p. 7).

However, the investigations of all aspects of the hydrological cycle under the framework of the IMPETUS project were carried out basically over two river basins namely Ouémé and Wadi Drâa in Benin and Morocco, respectively, due to the availability of data among other criteria (cf., Speth and Fink, 2010, p. 9). Further, hydrological studies over WA that employed Gravity Recovery and Climate Experiment (GRACE, Tapley et al., 2004) have also been documented (see, e.g., Ndehedehe et al., 2016a; Forootan et al., 2014a; Grippa et al., 2011). However, these studies are restricted to the last decade because of the limited GRACE-observations. Since WA is one of the tropical regions of the world characterised by strong inter-annual variability in rainfall, with an increasing potential of drought vulnerability (e.g., Ndehedehe et al., 2016b), a further investigation into the long term freshwater flux of WA is therefore warranted.

WA is a well known climatic hot spot, where the land-ocean-atmosphere coupling plays an important role, through the spatio-temporal changes in precipitation and evaporation, which frequently result in the modulation of rainfall gradients (Douville et al., 2006). Some studies (see, e.g., Ndehedehe et al., 2016c; Diatta and Fink, 2014; Nicholson et al., 2000; Janicot et al., 1996) have suggested a possible relationship between climate indices (e.g., Atlantic multi-decadal oscillation-AMO, Atlantic meridional mode-AMM, El Niño Southern Oscillation-ENSO, Pacific Decadal Oscillations-PDO, etc.) and rainfall 
extremes over WA. As the hydrological cycle is accelerating due to global changes in climate (see, e.g., Malhi and Wright, 2004), the perceived influence of such changes underscores the need for a long term quantitative assessment of freshwater flux in the region.

In this study, wavelet analysis is employed for the first time to provide a quantitative analysis of flux in freshwater (availability and variability) over WA at the sub-climatic scale using long-term multiresolution data (soil moisture, rainfall, temperature, evaporation, and NDVI) during the period of 1979 to 2010. The main objectives of this study are threefold, to (i) investigate the spatio-temporal variations of freshwater flux (referred henceforth as net-precipitation) over the entire WA region, (ii) investigate the impacts of ENSO on WA's freshwater and, (iii) analyze the co-variability between different parameters that influence variations in freshwater (i.e., net-precipitation, rainfall, temperature, evaporation, and ENSO index) in order to determine the nonlinear relationships between available freshwater and climate variability. To achieve these objectives, the wavelet approach (e.g., Torrence and Compo, 1998; Grinsted et al., 2004), which has shown some skills in identifying temporal variability and trends in hydrological signals (e.g., Beecham and Chowdhury, 2009; Szolgayová and Arlt, 2014) is employed to extract localized variations in the dominant modes of the assessed parameters.

The remainder of the study is organized as follows; following the introduction, the study area is presented in Section 2, followed by the data and method of analysis in Section 3. The results are presented in Section 4, and the study is concluded in Section 5.

\section{Study Area}

\subsection{Geography}

The WA region spans an area of approximately 6 million $\mathrm{km}^{2}$, roughly $20 \%$ of Africa's total land area (refer to Figure 1 for the location of WA) with a total population of about 290 million. The region lies between longitudes $18^{\circ} \mathrm{W}$ and $16^{\circ} \mathrm{E}$ and latitudes $3^{\circ} \mathrm{N}$ and $28^{\circ} \mathrm{N}$ and it is bounded in the west and south by the Atlantic Ocean, the north by the Sahara desert, and the east by the Central African nations of Chad and Cameroon. The topography of the region is mainly flat; most parts lie less than $300 \mathrm{~m}$ above m.s.l. with several isolated high points along the coastal areas. The main river of the region is the Niger, which drains an area of 2 million $\mathrm{km}^{2}$, and is shared by nine of the seventeen countries in the region. Other important rivers are the Gambia, Senegal, Comoe and Volta, which are shared respectively by three, four, four, and five riparian countries.

\section{[FIGURE 1 AROUND HERE.]}




\subsection{Climate}

The region of WA is traditionally partitioned into three sub-climatic zones (Meynadier et al., 2010), including: (1) the dry north, known as the Sahel, which lies just below the Sahara desert, (2) the Sudano transitional zone, and (3) the relatively wet Guinean zone located in the south. This wet and dry regions depends on the latitude and the distance from the Atlantic Ocean while the degree of aridity increases from south to north and to a lesser extent from west to east as reported by Menz (2010, p. 56). However, in order to gain a more localized perspective to variations in moisture conditions, the Kmeans clustering algorithm was used to reclassify the climatic zones by their annual rainfall amounts to maintain consistency with the general African sub-climatic classification (e.g., Wamukonya et al., 2006) and it is presented in Figure 1. Consequently in this contribution, the climatic zones have been classified as hyper-arid (HyA) in the north, arid, semi-arid (SA), dry sub-humid (DSH) and moist sub-humid (MSH) in the south. Generally, the hyper-arid sub-region coincide with the desert area; arid, Sahel; semi-arid, Sudano; the moist and dry sub-humid areas, Guinean (see Figure 1). Rainfall in the region is modulated by the northeast trade winds from the Sahara and the southwest monsoon winds from the Gulf of Guinea in a dipolar manner (see, e.g., Nicholson, 2013).

\section{Methods and Data}

\subsection{Datasets}

\subsubsection{ERA-Interim}

The European Centre for Medium-Range Weather Forecasts (ECMWF) Reanalysis dataset (ERAInterim) provides a third generation ocean-land-atmosphere processes reanalysis data for estimating mass, moisture, and energy budget products (Dee et al., 2011). Data fields of specific humidity, zonal $(U)$ and meridional $(V)$ components of wind at different pressure levels (i.e., from the Earth's surface to the top of the atmosphere) were used in this study to compute changes in atmospheric water storage and moisture flux divergence as described at Section 3.2.2. Additionally, temperature, evaporation, and soil moisture datasets from ERA-Interim were used in this study to understand the co-varying relationships with net-precipitation. The ERA-Interim datasets were obtained from http://apps.ecmwf.int/datasets/data/interim_full_moda/ for the period 1980 to 2010. The datasets were all retrieved at a gridded spatial resolution of $0.25^{\circ}$ at a monthly temporal interval.

\subsection{2. $G L D A S$}

The Global Land Data Assimilation System (GLDAS) products combines satellite and ground based observed data to generate optimal fields of land surface states and fluxes using advanced land surface 
modeling and data assimilation techniques (Rodell et al., 2004). It is driven by four land surface models (LSMs) namely the Variable Infiltration Capacity (VIC), Noah, Mosaic, and Community Land Model (CLM). The four LSMs output hydrological and meteorological fields at 1-degree and 0.25-degree resolutions, as well as a three-hourly and monthly temporal resolutions. The GLDAS model data are available from 1979 to the present. For this study, the monthly precipitation and evaporation fields at the $1^{\circ}$ resolution for the period 1979 to 2010 were used. The GLDAS data were retrieved from http://disc.sci.gsfc.nasa.gov/hydrology/data-holdings.

\subsubsection{Global precipitation Climatology Centre (GPCC)}

The precipitation data used in this study were obtained from the Global precipitation Climatology Centre (GPCC) and covers the period of 1979 to 2010. This data is made available by Deutscher Wetterdienst (DWD, National Meteorological Service of Germany) and include rain gauge data collected from national meteorological agencies (e.g. Becker et al., 2013). Other sources of inputs comprise of archives in the Global Telecommunication Systems (GTS), daily surface synoptic observations (SYNOP) messages, and monthly climatological data (CLIMAT messages). GPCC also utilizes published global datasets from the Food and Agriculture Organization (FAO) FAOCLIM 2.0, Climate Research Unit (CRU), Global Historical Network (GHCN), as well as several regional datasets, making it the most comprehensive quality controlled global gauge archive that is readily available (Becker et al., 2013). The precipitation products are provided at different time and spatial resolutions for specific applications (see, e.g., Becker et al., 2013; Schneider et al., 2013). This study used the Full Data Product (i.e., GPCC-FD) at a spatial resolution of $0.5^{\circ}$ and a monthly temporal resolution from 1980 to 2010 . The GPCC rainfall fields were retrieved from ftp://ftp-anon.dwd.de/pub/data/gpcc/html/download_gate.html.

\subsubsection{Multivariate ENSO Index (MEI)}

The El-Niño Southern Oscillation (ENSO) is a major coupled ocean-atmosphere phenomenon that causes global climate variability on inter-annual time scales. In this study, the Multivariate ENSO Index (MEI) was obtained from the Physical Sciences and Physical Oceanography divisions of the National Oceanic \& Atmospheric Administration (NOAA). MEI represents ENSO events based on six variables: sea-level pressure, zonal and meridional components of the surface wind, sea surface temperature, surface air temperature, and total cloudiness fraction of the sky (Wolter and Timlin, 2011). By adopting a multivariate approach, MEI provides a more complete and flexible description of the ENSO phenomenon (Wolter and Timlin, 2011). The cold (negative) phase (La Niña) results in wet period in WA, while the converse is true for the warm (positive) phase (El Niño) as observed by Nicholson (2013). The ENSO index time series (Figure 2) used in the study were retrieved from http://www.esrl.noaa.gov/psd/ enso/mei/. 


\subsubsection{Normalised Difference Vegetation Index (NDVI)}

Since moisture changes over the region are also highly coupled to changes in vegetation (e.g., Huber et al., 2011), variations in net-precipitation with respect to NDVI were assessed. NDVI time series covering the period of 1981 to 2006 were obtained from the Global Inventory Modeling and Mapping Studies (GIMMS). The GIMMS NDVI data is derived from satellite imagery generated from the Advanced Very High Resolution Radiometer (AVHRR) instrument on-board the NOAA satellite series 7, 9, $11,14,16$, and 17 at a 15 day and approximately $0.0833^{\circ}$ temporal and spatial resolutions, respectively (Tucker et al., 2005). The vegetation index data was retrieved from http://iridl.ldeo.columbia.edu/ SOURCES/.UMD/.GLCF/.GIMMS/.NDVIg/.global/.ndvi/index.html?.Set-Language=en and the bi-monthly dataset was aggregated to monthly series.

\subsection{Methodology}

Maximum renewable freshwater availability fields were derived from the atmospheric water budget approach and compared to the net-precipitation from GLDAS model's rainfall and evaporation datasets. All the gridded datasets, with the exception of the GLDAS products, were up-scaled (i.e., filtered with a low pass filter and re-sampled with the bi-cubic interpolation technique) to a spatial resolution of $0.5^{\circ}$ to ensure consistency with the GPCC rainfall data. In comparing the ERA-Interim and GLDAS products, the former was up-scaled to a coarser resolution of $1^{\circ}$. Next, continuous wavelet analyzes (Section 3.2.3) were then performed on the different data sets in order to investigate their wave power spectra patterns. Finally, cross coherencies between the datasets were also investigated with the wavelet coherence method (Section 3.2.4).

\subsubsection{Net-precipitation}

Net-precipitation can be obtained by the direct differencing of precipitation and evaporation (e.g., Meynadier et al., 2010; Morrow et al., 2011) or through the atmospheric water budget approach (e.g., Yirdaw et al., 2008; Syed et al., 2009; Munier et al., 2012). Comparing global runoff anomalies from the coupled atmospheric-terrestrial water budget, Munier et al. (2012) indicated consistency between net-precipitation from observed $P$ and modeled $E$. Meynadier et al. (2010) used modeled evaporation and Tropical Rainfall and Measuring Mission (TRMM) rainfall data and reported that the moisture flux divergence and precipitation minus evaporation are quite similar over WA.

Essentially, net-precipitation is a measure of the flux in the maximum available renewable freshwater resource (Oki and Kanae, 2006). Consequently, a system with a long term deficit in net-precipitation tends to face dry conditions and vice-versa (Lee et al., 2014). For this study, net-precipitation 
is computed as a residual of the atmospheric water balance using meteorological data from the ERA-

Interim. Additionally, net-precipitation was estimated from the land-based approach using the GLDAS models and compared to the ERA-Interim estimate. Our motivation to select the ERA-Interim reanalysis data to perform the investigations was due to its long term consistency as reported by Lorenz and Kunstmann (2012) and Forootan et al. (2014b). The evaporation estimates from GLDAS were used due to their acceptable uncertainty over WA as illustrated by Andam-Akorful et al. (2015).

\subsubsection{Atmospheric Water Budget}

From the atmospheric perspective, the instantaneous water balance equation is given as (e.g., Yirdaw et al., 2008):

$$
\frac{\partial W}{\partial t}+\nabla \cdot \mathbf{Q}=-(P-E),
$$

where $P$ and $E$ are precipitation and evaporation respectively, and $t$ represents time. $W$ is the atmospheric water storage obtained as the total water column in a unit area of the atmosphere, calculated as (e.g., Yirdaw et al., 2008):

$$
W=\frac{1}{g \rho} \int_{p_{s}}^{p_{t}} q \mathrm{~d} p,
$$

where the surface pressure, $p_{s}$ and the pressure at the top of the atmosphere, $p_{t}$ are the limits of the integral, $q$, which is the specific humidity; $g$, the gravity value and $\rho$, the density of water.

The moisture flux divergence (or convergence depending on its sign) or net outflow of water vapor across the atmosphere computed from specific humidity, the eastern, and northern direction winds (cf., Yirdaw et al., 2008, for details) is given by:

$$
\nabla \cdot \mathbf{Q}=\frac{1}{R \cos \varphi}\left(\frac{\partial Q_{\lambda}}{\partial \lambda}+\frac{\partial\left(Q_{\varphi} \cos \varphi\right)}{\partial \varphi}\right)
$$

where $Q_{\lambda}$ and $Q_{\varphi}$ represent the east-west and north-south components of vapour flux respectively. $R$ is the mean radius of the Earth, $\lambda$ and $\varphi$ are the longitude and latitude, respectively.

\subsubsection{Wavelet Transform}

Wavelet analysis allows the investigation of localized changes in sampled time series by decomposing them into time-frequency space (Jänicke et al., 2009). The frequency and time domains of hydroclimatic time series are usually non-stationary. As a result, the amplitude and frequency of the dominant periodic components of fluxes evolve in both space and time domains, making their identification using techniques such as Fourier Transforms or Least Square Spectral Analysis, very difficult (e.g., Beecham and Chowdhury, 2009; Sharifi et al., 2013). Wavelet transforms, in contrast, can be applied to identify localized 
changes from available observations by projecting them onto different resolutions (scales) base-functions that vary with respect to time and frequency (e.g., Torrence and Compo, 1998; Keller, 2004, p. 24). The continuous wavelet transform (CWT) was used, here, to compute the wave power spectrum (WPS) in order to quantify the distribution of variances in the available datasets such as net-precipitation and rainfall (Torrence and Compo, 1998). Mathematically, CWT is expressed as (Beecham and Chowdhury, 2009):

$$
C(a, b)=\frac{1}{\sqrt{a}} \int s(t) \psi\left(\frac{t-b}{a}\right) \mathrm{d} t,
$$

where $C$ is the wavelet coefficient, $a$ and $b$ are the scale and position functions respectively, $s(t)$ is the signal, and $\psi$ is the wavelet function. Morlet wavelet was used as the mother-wavelet since it is well suited for feature extraction from oscillatory samples such as the hydroclimatic time series employed in this study (e.g., Domingues et al., 2005; Jänicke et al., 2009). Seasonal fluctuations and short-term biases were removed before application of the wavelet analysis by standardizing the time series, i.e., their temporal mean values were removed and the resulting series scaled by their corresponding standard deviations (Nakken, 1999). For detailed explanations of wavelet analysis using WPS, we refer to Keller (2004) and Torrence and Compo (1998).

\subsubsection{Wavelet Coherence}

To identify co-varying relationships between net-precipitation and the other datasets, the wavelet squared coherency (WTC) algorithm was employed (Torrence and Webster, 1999; Grinsted et al., 2004). WTC between two CWTs is useful to locate significant coherence against a background of red noise (Grinsted et al., 2004). The WTC between two signals is given as (Grinsted et al., 2004):

$$
R_{n}^{2}(s)=\frac{\left|S\left(s^{-1} W_{n}^{X Y}(s)\right)\right|^{2}}{S\left(s^{-1}\left|W_{n}^{X}(s)\right|^{2}\right) \cdot S\left(s^{-1}\left|W_{n}^{Y}(s)\right|^{2}\right)},
$$

where $S$ is a smoothing operator, $W^{X Y}$, the cross wavelet transform between the two CWTs $W^{X}$ and $W^{Y}$, and $X$ and $Y$ represent the two time series (e.g., net-precipitation and temperature). Following Grinsted et al. (2004), the WTC can be seen as a localized correlation coefficient in a time-frequency space.

\subsubsection{Trend Analysis}

The Sen's slope estimator $(S e n, 1968)$ was used to determine trends in the power spectrum of each dataset. This method of robust linear regression estimation chooses the median slope among all lines through pairs of two dimensional points in a time series (Machiwal and Jha, 2012, p. 70). For an equally 
spaced time series, the slope estimator is defined as (Sen, 1968):

$$
f(t)=Q t+B,
$$

where $Q$ is the slope and $B$ is a constant. The slope rate - i.e., linear rate of change - $Q$, is obtained by finding the median of all the slopes of the data pairs as:

$$
Q_{i}=\frac{x_{j}-x_{k}}{t_{j}-t_{k}}, \quad i=1,2, \ldots, N, \quad N=\frac{n(n-1)}{2},
$$

for all $j>k, k=1,2, \ldots,(n-1)$, and $j=2,3, \ldots, n$, where $n$ and $N$ is the number of data and the number of slope estimations, respectively; and $x_{j}$ and $x_{k}$ are the measurements at times $t_{j}$ and $t_{k}$, respectively. Using the median for computation of $Q_{i}$ in Eq. (7) makes the estimation more robust to the outliers or extreme observations. The significance of the estimated $Q$ was tested using the Mann-Kendall test at a 95\% confidence interval (see, e.g., Machiwal and Jha, 2012, p. 69).

\subsubsection{Change Point Analysis}

Hydro-climatic sequences, which are the results of certain natural processes remain the same as long as conditions are steady. However, if the processes undergo significant changes, the sequences exhibit jumps and present different statistical properties (Wong et al., 2006). A change point analysis enables the estimation of the point at which the change(s) occur. We make use of the change point package by Killick and Eckley (2014) in the R statistical software to detect changes in the series studied in this paper.

\section{Results and Discussion}

The net-precipitation estimations from the atmospheric and land-based water budgets are first compared. The results of the wave power spectrum (WPS) of each data set (i.e., net-precipitation, rainfall, temperature, evaporation, soil moisture, and NDVI) and the analysis of mean changes of the data sets at the decadal scale, as well as their spatial trends in the wavelet transforms and signal coherency analysis are presented.

\subsection{Data Comparisons}

To compare different estimations of net-precipitation over WA, areal averages were computed from the GLDAS products (i.e., from the land-based water balance perspective) and ERA-Interim (atmospheric water balance approach). Although the five different datasets show some degree of consistency, there are 
significant differences in their estimates as can be seen in Figure 3. The CLM product for instance seems to overestimate net-precipitation, with most of its values being largely above zero. Similarly, Noah and Mosaic seem to overestimate the quantity while VIC's time series is the closest to that of ERA. For all the GLDAS products however, there seem to be a systematic error in the time series between 1996 and 1997 where the seasonal cycle was not adequately represented. This was also reported by Huang et al. (2013), who assessed the GLDAS-Noah and ERA-Interim time series over the Yangtze River Basin of China.

\section{[FIGURE 3 AROUND HERE.]}

In light of the performed comparisons (see, Figure 3), the ERA-Interim estimates were used for the rest of the analysis. However, further investigation is needed in order to find the sources of these differences. For example, uncertainties in the GLDAS-estimated evaporation fields come from various sources such as meteorological and surface data as well as the algorithm used (e.g., Xue et al., 2013).

\subsection{Spatially Averaged Temporal Analysis}

Figure 4 shows the results of the wavelet analysis derived from the areal averages of rainfall over WA. Dominant modes of the signal occur at the annual (maximum occurs at the 1 year period) and the semi-annual scales (maximum occurs at the 0.5 year period) as shown by Figure 4c. The variance of the seasonal cycle as presented in Figure 4d appears to be modulated by a low frequency oscillation, as its magnitude show peaks and troughs at a 2 to 8 year periodicity, which is consistent with the ENSO cycle (see Figure 2). Similarly, the annual variabilities follow this oscillation (Figures $4 \mathrm{~b}$ and $4 \mathrm{~d}$ ). In the early 1980s, the spectral power at the annual scale were of relatively low magnitudes, which corresponds to the 1982/83 drought in WA (Nicholson, 2013). Coincident with the comparatively wet period following the anomalously dry spell, higher annual amplitudes are observed for the second half of the decade, peaking around 1989. Weaker annual variances are then observed between 1990 to early 1993, rising to a peak in the third quarter of 1994 before dipping in 1997 and then again, rising to another peak in 1999 (see Figure 4d). Spectral signatures at the annual scale show a slight increasing linear trend as shown by Figure 4d. This signifies an increase in annual rainfall rates between 1983 and 2010, which was confirmed with the Mann-Kendall significance test.

\section{[FIGURE 4 AROUND HERE.]}

The wavelet transform results for net-precipitation over the entire region is presented in (Figure 5d). Similar to rainfall, most of the dominant spectral power is located at the annual and semi-annual time scales. Relatively weak sub-annual variances are observed before early 1984, followed by higher variances 
between the boreal summer of 1984 to early 1991. Relatively low amplitudes are observed between 1991

to early 1993 and 1994 to 1996 . From late 1995 to 2010, however, it is observed that the wavelet power within this period is significantly lower than the one between 1979 to 1995 . Similarly for the annual signals, the mean power before 1996 is found to be higher than those after this period (cf., Figure 5d), which implies that, the variance of water flux over the region reduced significantly since 1995 afterwards. A Mann-Kendall significance test showed a significant decrease in the averaged power of the net precipitation at the annual scale.

[FIGURE 5 AROUND HERE.]

A change point analysis was performed to detect the changes in both the mean and variance in the extracted averaged power at the annual cycle (Figure 6). Both tests divided the series into groups respectively at a confidence level of $95 \%$. The extracted rainfall flux returned a change point in April 1985, whereas that of net-precipitation was in April 1996.

\section{[FIGURE 6 AROUND HERE.]}

In order to confirm this apparent significant decrease in water flux variance, wavelet analyses were performed on evaporation, soil moisture change, temperature and NDVI time series. Figure 7 shows the WPS and the averaged signal power at the annual scale of the respective datasets. Figure 7 (a and b) shows relatively high temperature signal power during the 1980s and a significant dip in 1991 before experiencing a minimal positive trend. It is observed that the averaged annual scaled power (Figure $7 \mathrm{~b}$ ) shows a repetitive pattern of approximately 5 to 8 years. This is in agreement with ENSO activity, which presents cycles between 2 to 8 years. Signal power of evaporation during the drought years of the early 1980s was relatively low (Figure 7d), but experienced an increase in amplitude, which coincided with high rainfall power (see Figure 4). After a significant peak in 1988/89, we found a progressively decreasing trend in the variance of evaporation for the next 20 years (Figure 7d). The reduction in the variance of the evaporation signal could account for the lower variance in water flux. Similar patterns from soil moisture change, and NDVI (see Figure 7 panels e to h) with respect to net-precipitation and evaporation were observed.

\section{[FIGURE 7 AROUND HERE.]}

It can therefore be concluded here that, the increasing trend in rainfall variance is coherent with the decreasing trend in freshwater flux together with all other datasets (i.e., NDVI, evaporation and soil moisture changes). As variations in net-precipitation show two distinct regime periods (i.e., 1979 to 1995 and 1996 to 2010), an evaluation of the mean percentage changes in the four main parameters (i.e., 
net-precipitation, rainfall, temperature and evaporation) with respect to those periods was undertaken. Altogether, the mean monthly precipitation power at the annual scale between 1979 to 1995 and 1996 to 2010 increased by $4 \%$ while temperature increased by $8 \%$. The variances of evaporation, soil moisture change, and net-precipitation however decreased by $8 \%, 30 \%$ and $26 \%$, respectively (Table 1). Additionally, soil moisture flux from the different GLDAS models (not shown here) show a mean reduction in annual variance of 30\%. NDVI annual signal power between 1982 to 1995 and 1996 to 2006 decreased by $22 \%$. Thus, the decreased annual signal power of available freshwater in the region is confirmed by the wavelet transforms analyses of the different datasets.

\subsubsection{Sub-climatic Zones}

Since WA is a large region with different hydroclimatic regimes, wavelet analysis was performed on spatially averaged signals for each sub-climatic zone (see Figure 1) in order to identify the main source of variability in net-precipitation and rainfall. Figure 7 presents the 1-year scale-averaged wavelet spectral power in the respective zones. The power of rainfall in the moist sub-humid zone (including countries such as Guinea, Sierra Leone and Liberia) during the drought period of 1982/83, which coincided with a positive ENSO event, is expectedly low as compared to the period between 1984 to 2004 (Figure 8). Very low signal amplitudes are however observed between early 2004 and late 2005. The amplitude of rainfall then rose to a significant peak during 2007, coincident with the 2007's La Niña event (Paeth et al., 2011). The nature of the WPS of net-precipitation before 1993 was found to be largely consistent with that of rainfall (Figure 8b). Afterwards the annual signal variance show an inverse pattern till early 2004, after which, the two series exhibit similar troughs and peaks. Step change analysis (shown as dashed lines on the figure) indicated that no significant change in mean or variance occurred within the period of consideration for both series.

\section{[FIGURE 8 AROUND HERE.]}

For the dry sub-humid zone, whereas rainfall (Figure 8c) experienced a positive increase within the period of study, water availability (Figure 8d) decreased significantly. Rainfall in this zone experienced a positive change in mean power at epoch 1984.917 (i.e. December 1984), on the other hand, there was a negative change in net precipitation at 1995.750 (October, 1995). Similarly, the Sudano zone experienced increased rainfall power with a positive change in mean at 1987.667 (September, 1987) while net precipitation saw a negative step change at 2000.330 (May, 2000) as shown in Figure 8e and Figure 8f respectively. Rainfall (Figure 8g) in the Sahelian zone had a positive step change at 1988.000 (January 1988), whereas a negative change in mean and variance for the net precipitation series begun at 2005.750 (October, 2005), Figure 8f. The hyper-arid zone however, experienced positive changes in 
rainfall (Figure 8i) and net precipitation (Figure 8j) respectively at 1992.167 (March, 1992) and 1994.000 (January, 1994).

Overall, with the exception of the hyper-arid zone, the variances of rainfall at the annual scale show increasing trends, while those of net-precipitation show decreasing trends. This result is consistent with those from other data sets, presented in section 4.2. Furthermore, Figure 8 shows that, the rainfall deficits lasted for longer periods in the drier zones compared to the relatively moist ones. It is also important to note that, while rainfall and net-precipitation in the hyper-arid region both indicate increasing trends, their respective WPSs are negligible when the entire region is considered (refer to Table 1).

\section{[TABLE 1 AROUND HERE.]}

\subsubsection{Mean decadal changes at the annual scale}

Table 1 provides a summary of the changes in the annual scale signal variances of precipitation, temperature, evaporation, and net-precipitation for the respective zones between 1979 to 1996 and 1997 to 2010. The moist sub-humid zone experienced deficits in all the four quantities. The total contribution of this region to temperature and evaporation changes over WA are, however, nearly negligible. In contrast, its total contribution to rainfall and net-precipitation (of approximately $43 \%$ and $22 \%$, respectively) was found to be very significant despite the relatively small area it covers. This humid sub-climatic zone, which is located mostly in the southwestern highlands of WA is an important source for a number of rivers including the Niger, the Gambia and the Senegal (see, e.g., Simier et al., 2006; Sall et al., 2007; Oguntunde and Abiodun, 2012). Consequently, a reduction in rainfall signal power in this zone could have triggered the reduction of the variance of net precipitation over WA. It is worth noting that, this sub-region was not significantly affected by the reduced rainfall rates as it only experienced a minimal change $(-0.55 \%)$ in net-precipitation.

Meanwhile, the dry sub-humid zone experienced a 33.6\% deficit in net-precipitation variance. Conversely, rainfall, temperature and evaporation, however, increased by $2.69 \%, 10.26 \%$ and $4.36 \%$, respectively. Although its total rainfall power contribution to the region is slightly lower than that of the moist sub-humid zone, it contributes $63.34 \%$ to the total net-precipitation signal power. This is likely due to the fact that its land area is drained by the main rivers of WA (e.g., the Niger, Gambia, Senegal, and Volta). Accordingly, most of the observed reduction in available water over the region could be attributed to the net-precipitation deficit in this zone. The Sudano and Sahelian zones both exhibited positive changes in rainfall and temperature but negative for evaporation and net-precipitation. These two zones are mostly drained by rivers (e.g., Niger and Senegal) predominantly sourced from the more humid zones (moist and dry sub humid zones). Consequently, it is concluded that a possible reduction in runoff from the humid areas likely led to a deficit in freshwater availability in WA. 


\subsection{Spatial trends in signal variances}

Figure 9 presents the WPS spatial trends in rainfall, temperature, evaporation, net-precipitation, soil moisture and NDVI. Rainfall power mostly in the MSH and DSH zones along the coast (see Figure 9a) experienced decreasing trends, especially in the Guinean Highlands, which caused reduction in runoff into rivers that take their sources from this region. Conversely, most areas in the Sudano, Sahelian and desert regions experienced increased rainfall power. This observation agrees with the findings made in a number of studies, see, e.g., Nicholson (2005); Anyamba and Tucker (2005); Ali and Lebel (2008); Lebel and Ali (2009); Nicholson (2013). However, as observed in Section 4.2.2, rainfall in these zones represents a small portion of the total rainfall of the entire WA. Therefore, it did not significantly improve the water availability conditions in the region.

Temperature changes (Figure 9b) in the south western part of WA indicated decreasing trends, whereas parts of Mali, Côte d'Ivoire, Burkina Faso, Ghana, and Nigeria exhibited modest positive trends. The drier northern parts of the region largely had small negative or insignificant trends in terms of temperature. Evaporation (Figure 9c) rates experienced reduction in most parts of the region. Parts of the Sahel and desert areas experienced negative trends, consistent with our results from temperature changes. Although the dry north (specifically the Sahel and desert areas) largely experienced positive trends in net-precipitation, the north eastern and western areas both saw negative trends (Figure 9d). Areas lying along the western coast as well as the eastern coast indicated positive trends, while most of the MSH, DSH and Sudano zones exhibited negative trends. Most parts of the dry north experienced increasing trends, however, areas in the north eastern and north western parts exhibited decreasing trends in power.

\section{[FIGURE 9 AROUND HERE.]}

A high consistency was found between the trends in the vegetation index and those of rainfall and netprecipitation (Figures 9f, 9a, and 9d). Generally, the drier parts of the region seem to have experienced some degree of greening (i.e., positive trends of 5 to 15 square units in NDVI variance), whereas the humid south presented negative trends. The trends in the NDVI data set is largely consistent with those in rainfall and net-precipitation. The increased wetness and cooler temperatures in the arid and semi-arid parts of the region and the converse in the Guinean sub-regions agree with the findings of Huber et al. (2011).

\subsection{Decadal Changes}

In Figure 10, panels a to d, the deviations of rainfall, net-precipitation, evaporation and temperature from their 32-year means are plotted, respectively. It is evident from Figure 10a that, the amount of 
rainfall in the 1980s was less than the long term mean (i.e., from 1979 to 2010), with relatively higher rainfall rates in the following two decades. Low evaporation rates were also observed in the first decade, indicating a deficit in soil moisture and surface water for evaporation, whereas the higher rates of the following decade were likely due to availability of more water (Figure 10c). Coincident with higher temperatures from 2000, evaporation rates since 2003 were found to be consistently above the mean value for the 32 year period, which coincided with relatively lower rainfall rates in the 2000s. Similarly, the mean annual net-precipitation in the 1980s was lower than that of the 1990s, while the last decade (i.e., the 2000s) also presented lower amounts (Figure 10b).

\section{[FIGURE 10 AROUND HERE.]}

With respect to Table 2, the mean annual rainfall in the first decade (i.e., 1979 to 1989) increased by $7 \%$, and $3.7 \%$ in the second (i.e., 1990 to 1999) but fell by $3.3 \%$ in the third decade, whereas temperature had a cumulative rise of $0.14 \%$ in the last decade (i.e., 2000 to 2010). The mean annual evaporation increased by $3.59 \%$ and $0.82 \%$ leading to a cumulative rise of $4.41 \%$ by the third decade. It is, therefore, apparent that reducing rainfall rates coupled with rising temperatures, and consequently evaporation, led to $30.86 \%$ decrease in net-precipitation with respect to the second and third decades and a cumulative reduction of $10.54 \%$ since the 1980s. Taking into account observations made in Section 4.2.2, decreasing rainfall rates in the humid climatic zone and rising temperatures in the other zones resulted in increased evaporation rates and consequently reduced the amount of maximum available freshwater in WA.

\section{[TABLE 2 AROUND HERE.]}

\subsection{Signal Coherencies}

Coherency between spatially averaged time series between 4 data sets (i.e. rainfall, net-precipitation, temperature and evaporation) as well as ENSO index are shown in Figure 11. Wavelet coherency (WTC) between rainfall and MEI (Figure 11a) shows limited coherency between the two parameters at the annual and seasonal scales (i.e. around periods 1 and 0.5 years, respectively). However, significant coherence at the annual scale can be observed between late 1988 and early 1991, coincident with the La Niña event between 1988 and 1989 (see Figure 2b). This is in agreement with the findings of Nicholson et al. (2000), who reported relatively high rainfall amounts during those years. High co-varying power is also observed between mid 1999 and early 2001, also coincident with the La Niña event between $1998 / 1999$.

\section{[FIGURE 11 AROUND HERE.]}


At the seasonal scale however, the region of high co-variability between 1992 and 1995 are found to be anti-correlated. This period coincides with the moderate ENSO events (see Figure 2). This implies that although the seasonal rainfall was significantly affected, the ENSO effect was not significant at the annual scale. Conversely, the moderate La Niña events between 2007 and 2008 seem to present positive impacts both on the seasonal and annual rainfall between overlapping periods in 2005 and 2009 (cf., Samimi et al., 2012; Paeth et al., 2011).

At the three to five year cycle, rainfall and MEI are approximately six months out of phase between 1979 and 1984 (although parts of the significant area is outside the COI due to the length of the time series), indicating the extreme dry conditions that coincided with the 1982/1983 ENSO event. Additionally, from 1995 to 2010 (note that 2005-2010 is outside the COI), ENSO is approximately 10 months out of phase with rainfall. This is consistent with low rainfall amounts in the last decade as found in Section 4.4. Consequently, it can be inferred that the warm phase of ENSO during the two different periods resulted in dry conditions in the 1980s, as well as the mid 1990s to the present decade. This period of low rainfall amplitudes coincides with the low net-precipitation signal power as reported in Section 4.2. It can be concluded therefore, that low frequency modulation of rainfall by ENSO activity from late 1995 played a major role in the observed reduction in available water within WA.

The WTC between net-precipitation and MEI at the annual and seasonal scales generally follow the same pattern as rainfall except over the years between 2004 and 2010 at the 2 year band, where it is estimated to be about 10 months out of phase. The characteristics of this coherency is similar to the one observed between 1979 and 1985 (the period before August 1983 is outside the COI), where a relatively low net-precipitation power was found. Thus, it can be deduced that this could be due to a low frequency oscillation which is associated with dry conditions in WA. The coherency of evaporation and MEI at the annual scale largely resemble that of rainfall and MEI, which generally indicates that, evaporation rates increase with increasing rainfall in agreement with Meynadier et al. (2010). Consequently, evaporation rates may show positive correlation with respect to rainfall and by extension, net-precipitation. However, sustained high evaporation rates during periods of low rainfall may lead to rapid moisture depletion (Otkin et al., 2013). The Lake Chad basin, for example, is one of such areas in WA where high evaporation rates due to low humidity and high temperatures can sometimes result in soil moisture deficits even during periods of significant increase in rainfall (Ndehedehe et al., 2016b).

Although the derived regions of high coherency are similar to rainfall/MEI WTC, the phase differences are reversed at the intra-annual scale. This can be seen between the years 1992 and 1994, where low evaporation rates are observed after moderate ENSO events. Similar relationships can be observed at the seasonal level between 2007 and 2009. No significant coherency was, however, established between the 2 parameters at the 2 to 7 year band, meaning that ENSO did not introduce significant long term 
modulating effects on evaporation as it does on rainfall.

Figures $11 \mathrm{~d}$ to $11 \mathrm{f}$ show the multi-resolution coherency between net-precipitation in relation to rainfall, temperature and evaporation, respectively. We found significant in-phase coherency between netprecipitation and rainfall at both the annual and sub-annual scale, whereas it precedes peak temperatures by $\sim 80^{\circ}$ and lags evaporation by $\sim 60^{\circ}$ at the intra-annual scale. The annual scale coherency with temperature indicates a phase difference of $\sim 60^{\circ}$ and a phase difference of $\sim 120^{\circ}$ with evaporation. At the 4 to 7 year band in Figure 11d, rainfall and net-precipitation show a strong co-variance between 1992 and 2005, which is reflected in the evaporation/net-precipitation WTC (Figure 11f). Taking into account the adverse ENSO impact on rainfall in Figure 10a, a joint reduction in the amplitude of net-precipitation and rainfall can be concluded. The observed co-variance between $P-E$ and evaporation around the 4 to 7 year band may be due to anthropogenic influences (such as human withdrawals and land use/land cover changes) since no obvious changes were found, as shown in either $\mathrm{MEI} / E$ or temperature/ $E$ in Figures 11c and 11i, respectively. This however, should be confirmed with a land cover change analysis, which is the subject of an ongoing study.

In Figure 11g, evaporation and rainfall indicate strong coherence in the late 1980s to the early 1990s. The signal characteristics, however, change to reflect similar patterns observed for the 4 to 8 year band during the dry early 1980s (outside the COI) from around 1994 to 2001 (similar to observations made in Figures 11d and 11f). Consequently, it can be inferred that the low frequency oscillation, associated with reduced net-precipitation power was likely caused by a moderate and slowly evolving ENSO activity that resulted in lower rainfall coupled with high evaporation rates in the 3 to 7 year band. Temperature/rainfall coupling in Figure 11h show an inversed relationship especially around the 3 to 7 year cycle till the mid 1990s, followed by a brief period of low coherency between 1996 and 2001 (note that this was the period in which the lowest net-precipitation amplitudes were observed) and high coherence from 2001 till 2005. Hence, it can be deduced that, although temperature increased slightly in WA, its impact on water availability may not be as strong as lower rainfall induced by the ENSO activity. A recent study over WA during the 2002 - 2014 period confirms that high precipitation rates, induced by ocean circulations, remain principal drivers of the region's stored water (Ndehedehe et al., 2016a). The extent to which anthropogenic activities contributed to the reduction of available water is however, not covered in this study as it is the subject of further studies.

\section{Conclusions}

The purpose of this study was to provide a synoptic view of current trends and variabilities in freshwater availability in West Africa. Specifically, in this contribution, the variability of available water expressed in terms of net-precipitation over the region has been investigated using wavelet analysis. 
Continuous wavelet transforms at the annual scale indicated that, although rainfall rates marginally

increased between 1979 and 2010, available water in the hydrological system of the region reduced considerably. The observed reduction in net-precipitation was confirmed with similar patterns in soil moisture and NDVI, which are two critical indicators of available water. Additionally, the wavelet power spectrum of spatially averaged temperature showed a slight positive trend while evaporation had a considerable negative trend. Spatially, the wavelet analysis at the annual scale showed that the dry northern part of the region largely experienced positive trends in freshwater availability whereas the relatively wet south experienced negative trends.

Mean standardized anomalies of the different data sets revealed that the 1990s experienced a recovery from the droughts of the 1980s, whereas the last decade was substantially dry. Wavelet coherency analysis, however, revealed that the reduction in net-precipitation power was highly coupled to lower rainfall rates induced by a moderate and slowly evolving ENSO activity that begun in 1995 as well as low frequency high evaporation rates. Since most major rivers (e.g., Comoe, Gambia, Niger, Senegal and Volta) in West Africa are fed from this area (i.e., south western Guinean zone), the reduced rainfall rates translated to a reduction in available water over West Africa. To further clarify the influence from anthropogenic sources, consideration of land use/land cover changes on the hydrological dynamics at the sub-climatic scale as well as evaluation of variabilities in the various components of total water-storage will be the subject of future studies.

\section{Acknowledgements}

V.G. Ferreira acknowledges funding support from the National Natural Science Foundation of China (Grant Nos. 41204016 and 41574001) and from the Fundamental Research Funds for the Central Universities (Grant No. 2015B21014). S.A. Andam-Akorful is grateful to Hohai University for his Ph.D. funding. C.E. Ndehedehe expresses his sincere gratitude to Curtin University for his $\mathrm{PhD}$ funding through the Curtin Strategic International Research Scholarship (CSIRS). We also extend our appreciations to the scientists and engineers at NASA, ECWMF, GPCC, NOAA, GIMMS for the GLDAS, meteorological, precipitation, MEI and NDVI datasets. Finally, we would like to thank the following people for their support on the early version of this work: Prof. Joseph L. Awange, Curtin University; Prof. Richard Anyah, University of Connecticut; and Ehsan Forootan, Bonn University. We thank Prof. Ian G. McKendry (Associate Editor) and two anonymous reviewers for their constructive comments that helped us to improve the article. Without those help this work would never have been possible. 


\section{References}

Ali, A., and T. Lebel (2008), The Sahelian standardized rainfall index revisited, International Journal of Climatology, 29(12), 1705-1714, doi:10.1002/joc.1832.

Amogu, O., L. Descroix, K. S. Yéro, E. Le Breton, I. Mamadou, A. Ali, T. Vischel, J.-C. Bader, I. B. Moussa, E. Gautier, S. Boubkraoui, and P. Belleudy (2010), Increasing river flows in the Sahel?, Water, 2(2), 170-199, doi:10.3390/w2020170.

Andam-Akorful, S. A., V. G. Ferreira, J. Awange, E. Forootan, and X. F. He (2015), Multi-model and multi-sensor estimation of evapotranspiration over the Volta Basin, West Africa, International Journal of Climatology, 35(10), 3132-3145, doi:10.1002/joc.4198.

Anyamba, A., and C. J. Tucker (2005), Analysis of Sahelian vegetation dynamics using NOAA-AVHRR NDVI data from 1981 - 2003, Journal of Arid Environments, 63, 596-614, doi:10.1016/j.jaridenv.2005. 03.007 .

Becker, A., P. Finger, A. Meyer-Christoffer, B. Rudolf, K. Schamm, U. Schneider, and M. Ziese (2013), A description of the global land-surface precipitation data products of the Global Precipitation Climatology Centre with sample applications including centennial (trend) analysis from 1901-present, Earth Syst. Sci. Data, 5(1), 71-99, doi:10.5194/essd-5-71-2013.

Beecham, S., and R. K. Chowdhury (2009), Temporal characteristics and variability of point rainfall: a statistical and wavelet analysis, International Journal of Climatology, 30(3), 458-473, doi:10.1002/ joc.1901.

Boone, A., B. Decharme, F. Guichard, P. de Rosnay, G. Balsamo, A. Beljaars, F. Chopin, T. Orgeval, J. Polcher, C. Delire, A. Ducharne, S. Gascoin, M. Grippa, L. Jarlan, L. Kergoat, E. Mougin, Y. Gusev, O. Nasonova, P. Harris, C. Taylor, A. Norgaard, I. Sandholt, C. Ottlé, I. Poccard-Leclercq, S. SauxPicart, and Y. Xue (2009), The AMMA Land Surface Model Intercomparison Project (ALMIP), Bulletin of the American Meteorological Society, 90(12), 1865-1880, doi:10.1175/2009BAMS2786.1.

Conway, D., A. Persechino, S. Ardoin-Bardin, H. Hamandawana, C. Dieulin, and G. Mahé (2009), Rainfall and Water Resources Variability in Sub-Saharan Africa during the Twentieth Century, Journal of Hydrometeorology, 10(1), 41-59, doi:10.1175/2008JHM1004.1.

Dee, D. P., S. M. Uppala, A. J. Simmons, P. Berrisford, P. Poli, S. Kobayashi, U. Andrae, M. A. Balmaseda, G. Balsamo, P. Bauer, P. Bechtold, A. C. M. Beljaars, L. van de Berg, J. Bidlot, N. Bormann, C. Delsol, R. Dragani, M. Fuentes, A. J. Geer, L. Haimberger, S. B. Healy, H. Hersbach, E. V. Hlm, L. Isaksen, P. Kllberg, M. Khler, M. Matricardi, A. P. McNally, B. M. Monge-Sanz, J.-J. Morcrette, 
B.-K. Park, C. Peubey, P. de Rosnay, C. Tavolato, J.-N. Thpaut, and F. Vitart (2011), The ERAinterim reanalysis: configuration and performance of the data assimilation system, Quarterly Journal of the Royal Meteorological Society, 137(656), 553-597, doi:10.1002/qj.828.

Descroix, L., G. Mahé, T. Lebel, G. Favreau, S. Galle, E. Gautier, J.-C. Olivry, J. Albergel, O. Amogu, B. Cappelaere, R. Dessouassi, A. Diedhiou, E. Le Breton, I. Mamadou, and D. Sighomnou (2009), Spatio-temporal variability of hydrological regimes around the boundaries between Sahelian and Sudanian areas of West Africa: A synthesis, Journal of Hydrology, 375(1-2), 90-102, doi:10.1016/j.jhydrol.2008.12.012.

Diatta, S., and A. H. Fink (2014), Statistical relationship between remote climate indices and West African monsoon variability, International Journal of Climatology, 34(12), 3348-3367, doi:10.1002/ joc.3912.

Domingues, M. O., O. Mendes, and A. M. da Costa (2005), On wavelet techniques in atmospheric sciences, Advances in Space Research, 35, 831-842, doi:10.1016/j.asr.2005.02.097.

Douville, H., S. Conil, S. Tyteca, and A. Voldoire (2006), Soil moisture memory and West African monsoon predictability: artefact or reality?, Climate Dynamics, 28(7-8), 723-742, doi:10.1007/ s00382-006-0207-8.

Forootan, E., J. Kusche, I. Loth, W.-D. Schuh, A. Eicker, J. Awange, L. Longuevergne, B. Diekkrüger, M. Schmidt, and C. Shum (2014a), Multivariate prediction of total water storage changes over West Africa from multi-satellite data, Surveys in Geophysics, 35, 913-940, doi:10.1007/s10712-014-9292-0.

Forootan, E., O. Didova, M. Schumacher, J. Kusche, and B. Elsaka (2014b), Comparisons of atmospheric mass variations derived from ECMWF reanalysis and operational fields, over 2003-2011, Journal of Geodesy, 88(5), 503-514, doi:10.1007/s00190-014-0696-x.

Grinsted, A., J. C. Moore, and S. Jevrejeva (2004), Application of the cross wavelet transform and wavelet coherence to geophysical time series, Nonlinear Processes in Geophysics, 11(5/6), 561-566, doi:10.5194/npg-11-561-2004.

Grippa, M., L. Kergoat, F. Frappart, Q. Araud, A. Boone, P. de Rosnay, J.-M. Lemoine, S. Gascoin, G. Balsamo, C. Ottlé, B. Decharme, S. Saux-Picart, and G. Ramillien (2011), Land water storage variability over West Africa estimated by Gravity Recovery and Climate Experiment (GRACE) and land surface models, Water Resources Research, 47(5), W05,549, doi:10.1029/2009WR008856.

Herrmann, S. M., A. Anyamba, and C. J. Tucker (2005), Recent trends in vegetation dynamics in the African Sahel and their relationship to climate, Global Environmental Change, 15(4), 394 - 404, doi:10.1016/j.gloenvcha.2005.08.004. 
Huang, Y., M. S. Salama, M. S. Krol, R. van der Velde, A. Y. Hoekstra, Y. Zhou, and Z. Su (2013), Analysis of long-term terrestrial water storage variations in the Yangtze River basin, Hydrology and Earth System Sciences, 17(5), 1985-2000, doi:10.5194/hess-17-1985-2013.

Huber, S., R. Fensholt, and K. Rasmussen (2011), Water availability as the driver of vegetation dynamics in the African Sahel from 1982 to 2007, Global and Planetary Change, 76 (34), 186 - 195, doi:10.1016/ j.gloplacha.2011.01.006.

Jänicke, H., M. Böttinger, U. Mikolajewicz, and G. Scheuermann (2009), Visual exploration of climate variability changes using wavelet analysis, IEEE transactions on visualization and computer graphics, 15(6), 1375-1382, doi:10.1109/TVCG.2009.197.

Janicot, S., V. Moron, and B. Fontaine (1996), Sahel droughts and ENSO dynamics, Geophysical Research Letters, 23(5), 515-518, doi:10.1029/96GL00246.

Kaspersen, P. S., R. Fensholt, and S. Huber (2011), A spatiotemporal analysis of climatic drivers for observed changes in Sahelian vegetation productivity (1982-2007), International Journal of Geophysics, 2011, 1-14, doi:10.1155/2011/715321.

Keller, W. (2004), Wavelets in Geodesy and Geodynamics, De Gruyter, Berlin, Boston.

Killick, R., and I. A. Eckley (2014), changepoint: An r package for changepoint analysis, Journal of Statistical Software, 58(3).

Lebel, T., and A. Ali (2009), Recent trends in the Central and Western Sahel rainfall regime (1990-2007), Journal of Hydrology, 375(12), 52 - 64, doi:10.1016/j.jhydrol.2008.11.030, surface processes and water cycle in West Africa, studied from the AMMA-CATCH observing system.

Lebel, T., B. Cappelaere, S. Galle, N. Hanan, L. Kergoat, S. Levis, B. Vieux, L. Descroix, M. Gosset, E. Mougin, C. Peugeot, and L. Seguis (2009), AMMA-CATCH studies in the Sahelian region of WestAfrica: An overview , Journal of Hydrology, 375(12), 3 - 13, doi:doi:10.1016/j.jhydrol.2009.03.020.

Lee, T. M., L. A. Sacks, and A. Swancar (2014), Exploring the long-term balance between net precipitation and net groundwater exchange in Florida seepage lakes, Journal of Hydrology, 519, Part D, 3054-3068, doi:http://dx.doi.org/10.1016/j.jhydrol.2014.04.009.

Lorenz, C., and H. Kunstmann (2012), The Hydrological Cycle in Three State-of-the-Art Reanalyses: Intercomparison and Performance Analysis, Journal of Hydrometeorology, 13(5), 1397-1420, doi:10. 1175/JHM-D-11-088.1.

Machiwal, D., and M. K. Jha (2012), Methods for Time Series Analysis, pp. 51-84, Springer Netherlands, Dordrecht, doi:10.1007/978-94-007-1861-6_4. 
Mahé, G., and J.-C. Olivry (1999), Assessment of freshwater yields to the ocean along the intertropical Atlantic coast of Africa (1951-1989), Comptes Rendus de l'Acadmie des Sciences - Series IIA - Earth and Planetary Science, 328(9), 621 - 626, doi:dx.doi.org/10.1016/S1251-8050(99)80159-1.

Mahé, G., and J.-E. Paturel (2009), 1896-2006 Sahelian annual rainfall variability and runoff increase of Sahelian Rivers, Comptes Rendus Geoscience, 341(7), 538-546, doi:http://dx.doi.org/10.1016/j.crte. 2009.05.002.

Mahé, G., J.-E. Paturel, E. Servat, D. Conway, and A. Dezetter (2005), The impact of land use change on soil water holding capacity and river flow modelling in the Nakambe River, Burkina-Faso, Journal of Hydrology, 300(1-4), 33-43, doi:10.1016/j.jhydrol.2004.04.028.

Malhi, Y., and J. Wright (2004), Spatial patterns and recent trends in the climate of tropical rainforest regions, Philosophical Transactions of the Royal Society of London, 359, 311329, doi:10.1098/rstb.2003.1433.

Menz, G. (2010), Regional geography of West and Northwest Africa: An introduction, in Impacts of Global Change on the Hydrological Cycle in West and Northwest Africa, edited by P. Speth, M. Christoph, and B. Diekkrüger, pp. 30-103, Springer Berlin Heidelberg, Berlin, Heidelberg, doi: 10.1007/978-3-642-12957-5_3.

Meynadier, R., O. Bock, F. Guichard, A. Boone, P. Roucou, and J.-L. Redelsperger (2010), West African Monsoon water cycle: 1. A hybrid water budget data set, Journal of Geophysical Research: Atmospheres, 115(D19), D19,106, doi:10.1029/2010JD013917.

Morrow, E., J. X. Mitrovica, and G. Fotopoulos (2011), Water Storage, Net Precipitation, and Evapotranspiration in the Mackenzie River Basin from October 2002 to September 2009 Inferred from GRACE Satellite Gravity Data, Journal of Hydrometeorology, 12(3), 467-473, doi:10.1175/ 2010JHM1278.1.

Munier, S., H. Palanisamy, P. Maisongrande, A. Cazenave, and E. F. Wood (2012), Global runoff anomalies over 1993-2009 estimated from coupled land-ocean-atmosphere water budgets and its relation with climate variability, Hydrology and Earth System Sciences, 16(10), 3647-3658, doi: 10.5194/hess-16-3647-2012.

Nakken, M. (1999), Wavelet analysis of rainfall-runoff variability isolating climatic from anthropogenic patterns, Environmental Modelling \& Software, 14(4), 283-295, doi:10.1016/S1364-8152(98)00080-2.

Ndehedehe, C., J. Awange, N. Agutu, M. Kuhn, and B. Heck (2016a), Understanding changes in terrestrial water storage over West Africa between 2002 and 2014, Advances in Water Resources, 88, 211-230, doi:10.1016/j.advwatres.2015.12.009. 
Ndehedehe, C. E., N. O. Agutu, O. H. Okwuashi, and V. G. Ferreira (2016b), Spatio-temporal variability of droughts and terrestrial water storage over Lake Chad Basin using independent component analysis, Journal of Hydrology, 540, 106- 128, doi:10.1016/j.jhydrol.2016.05.068.

Ndehedehe, C. E., J. L. Awange, R. Corner, M. Kuhn, and O. Okwuashi (2016c), On the potentials of multiple climate variables in assessing the spatio-temporal characteristics of hydrological droughts over the Volta Basin, Science of the Total Environment, 557-558, 819-837, doi:10.1016/j.scitotenv.2016.03.004.

Nicholson, S. (2005), On the question of the recovery of the rains in the West African Sahel, Journal of Arid Environments, 63(3), 615-641, doi:10.1016/j.jaridenv.2005.03.004.

Nicholson, S. E. (2013), The West African Sahel: A review of recent studies on the rainfall regime and its interannual variability, ISRN Meteorology, 2013, 1-32, doi:10.1155/2013/453521.

Nicholson, S. E., B. Some, and B. Kone (2000), An Analysis of recent rainfall conditions in West Africa, including the rainy Seasons of the 1997 El Niño and the 1998 La Niña Years, Journal of Climate, 13(14), 2628-2640, doi:10.1175/1520-0442(2000)013〈2628:AAORRC $\rangle 2.0 . C O ; 2$.

Oguntunde, P. G., and B. J. Abiodun (2012), The impact of climate change on the Niger River Basin hydroclimatology, West Africa, Climate Dynamics, 40(1-2), 81-94, doi:10.1007/s00382-012-1498-6.

Oki, T., and S. Kanae (2006), Global hydrological cycles and world water resources, Science, 313(5790), 1068-1072, doi:10.1126/science.1128845.

Otkin, J. A., M. C. Anderson, C. Hain, I. E. Mladenova, J. B. Basara, and M. Svoboda (2013), Examining rapid onset drought development using the thermal infrared-based evaporative stress index, Journal of Hydrometeorology, 14 (4), 1057-1074, doi:10.1175/JHM-D-12-0144.1.

Oyebande, L. (2001), Water problems in Africa - how can the sciences help?, Hydrological Sciences Journal, 46(6), 947-962, doi:10.1080/02626660109492888.

Paeth, H., A. H. Fink, S. Pohle, F. Keis, H. Mächel, and C. Samimi (2011), Meteorological characteristics and potential causes of the 2007 flood in sub-Saharan Africa, International Journal of Climatology, 31(13), 1908-1926, doi:10.1002/joc.2199.

Rodell, M., P. R. Houser, U. Jambor, J. Gottschalck, K. Mitchell, C.-J. Meng, K. Arsenault, B. Cosgrove, J. Radakovich, M. Bosilovich, and et al. (2004), The global land data assimilation system, Bulletin of the American Meteorological Society, 85(3), 381-394, doi:10.1175/BAMS-85-3-381.

Roudier, P., A. Ducharne, and L. Feyen (2014), Climate change impacts on runoff in West Africa: a review, Hydrology and Earth System Sciences, 18(7), 2789-2801, doi:10.5194/hess-18-2789-2014. 
Sall, S. M., A. Viltard, and H. Sauvageot (2007), Rainfall distribution over the Fouta Djallon Guinea, Atmospheric Research, 86(2), 149-161, doi:10.1016/j.atmosres.2007.03.008.

Samimi, C., A. H. Fink, and H. Paeth (2012), The 2007 flood in the Sahel: causes, characteristics and its presentation in the media and FEWS NET, Natural Hazards and Earth System Science, 12(2), 313-325, doi:10.5194/nhess-12-313-2012.

Schneider, U., A. Becker, P. Finger, A. Meyer-Christoffer, M. Ziese, and B. Rudolf (2013), GPCC's new land surface precipitation climatology based on quality-controlled in situ data and its role in quantifying the global water cycle, Theoretical and Applied Climatology, pp. 15-40, doi:10.1007/ s00704-013-0860-x.

Sen, P. (1968), Estimates of the regression co-efficient based on Kendall's tau, American Statistical Association, 63(324), 1379-1389, doi:10.1080/01621459.1968.10480934.

Sharifi, M., E. Forootan, M. Nikkhoo, J. Awange, and M. Najafi-Alamdari (2013), A point-wise least squares spectral analysis (LSSA) of the Caspian Sea level fluctuations, using TOPEX/Poseidon and Jason-1 observations, Advances in Space Research, 51(5), 858-873, doi:10.1016/j.asr.2012.10.001.

Shiferaw, B., K. Tesfaye, M. Kassie, T. Abate, B. Prasanna, and A. Menkir (2014), Managing vulnerability to drought and enhancing livelihood resilience in sub-Saharan Africa:technological, institutional and policy options, Weather and Climate Extremes, 3(0), 67-79, doi:10.1016/j.wace.2014.04.004.

Simier, M., C. Laurent, J.-M. Ecoutin, and J.-J. Albaret (2006), The Gambia River estuary: A reference point for estuarine fish assemblages studies in West Africa, Estuarine Coastal and Shelf Science, 69, 615-628, doi:10.1016/j.ecss.2006.05.028.

Speth, P., and A. H. Fink (2010), Introduction, in Impacts of Global Change on the Hydrological Cycle in West and Northwest Africa, edited by P. Speth, M. Christoph, and B. Diekkrüger, pp. 4-11, Springer Berlin Heidelberg, Berlin, Heidelberg, doi:10.1007/978-3-642-12957-5_1.

Syed, T. H., J. S. Famiglietti, and D. P. Chambers (2009), GRACE-based estimates of terrestrial freshwater discharge from basin to continental scales, Journal of Hydrometeorology, 10(1), 22-40, doi: 10.1175/2008JHM993.1.

Szolgayová, E., and J. Arlt (2014), Wavelet based deseasonalization for modelling and forecasting of daily discharge series considering long range dependence, Journal of Hydrology and Hydromechanics, 62(1), 24-32, doi:10.2478/johh-2014-0011.

Tapley, B., S. Bettadpur, M. Watkins, and C. Reigber (2004), The Gravity Recovery and Climate Experiment: Mission overview and early results, Geophysical Research Letters, 31, 1-4, doi:10.1029/ 2004GL019920. 
Torrence, C., and G. Compo (1998), A practical guide to wavelet analysis, Bulletin of the American Meteorological Society, 79(1), 61-78, doi:10.1175/1520-0477(1998)079〈0061:APGTWA $\rangle 2.0 . C O ; 2$.

Torrence, C., and P. J. Webster (1999), Interdecadal Changes in the ENSO-Monsoon System, Journal of Climate, 12(8), 2679-2690, doi:10.1175/1520-0442(1999)012〈2679:ICITEM $\rangle$ 2.0.CO;2.

Tucker, C., J. Pinzon, M. Brown, D. Slayback, E. Pak, R. Mahoney, E. Vermote, and N. El Saleous (2005), An extended AVHRR 8-km NDVI dataset compatible with MODIS and SPOT vegetation NDVI data, International Journal of Remote Sensing, 26, 4485-4498, doi:10.1080/01431160500168686.

Wamukonya, N., B. Masumbuko, E. Gowa, and J. Asamoah (2006), Environmental state-and-trends: 20year retrospective, in Africa Environment Outlook 2: Our Environment, Our Wealth, edited by J. C. Mohamed-Katerere and M. Sabet, chap. Atmosphere, pp. 48-50, DEWA/UNEP, Nairobi, Kenya.

Wittig, R., K. König, M. Schmidt, and J. Szarzynski (2007), A study of climate change and anthropogenic impacts in West Africa, Environmental Science and Pollution Research - International, 14(3), 182189, doi:10.1065/espr2007.02.388.

Wolter, K., and M. S. Timlin (2011), El Niño/Southern Oscillation behaviour since 1871 as diagnosed in an extended multivariate ENSO index (MEI.ext), International Journal of Climatology, 31(7), 1074-1087, doi:10.1002/joc.2336.

Wong, H., B. Hu, W. Ip, and J. Xia (2006), Change-point analysis of hydrological time series using grey relational method, Journal of Hydrology, 324 (1-4), 323-338.

Xue, B.-L., L. Wang, X. Li, K. Yang, D. Chen, and L. Sun (2013), Evaluation of evapotranspiration estimates for two river basins on the tibetan plateau by a water balance method, Journal of Hydrology, 492, 290-297, doi:http://dx.doi.org/10.1016/j.jhydrol.2013.04.005.

Yirdaw, S., K. Snelgrove, and C. Agboma (2008), GRACE satellite observations of terrestrial moisture changes for drought characterization in the Canadian Prairie, Journal of Hydrology, 356, 84-92, doi: 10.1016/j.jhydrol.2008.04.004.

Zhou, L., Y. Tian, R. B. Myneni, P. Ciais, S. Saatchi, Y. Y. Liu, S. Piao, H. Chen, E. F. Vermote, C. Song, and T. Hwang (2014), Widespread decline of congo rainforest greenness in the past decade, Nature, 509(7498), 86-90, doi:10.1038/nature13265. 


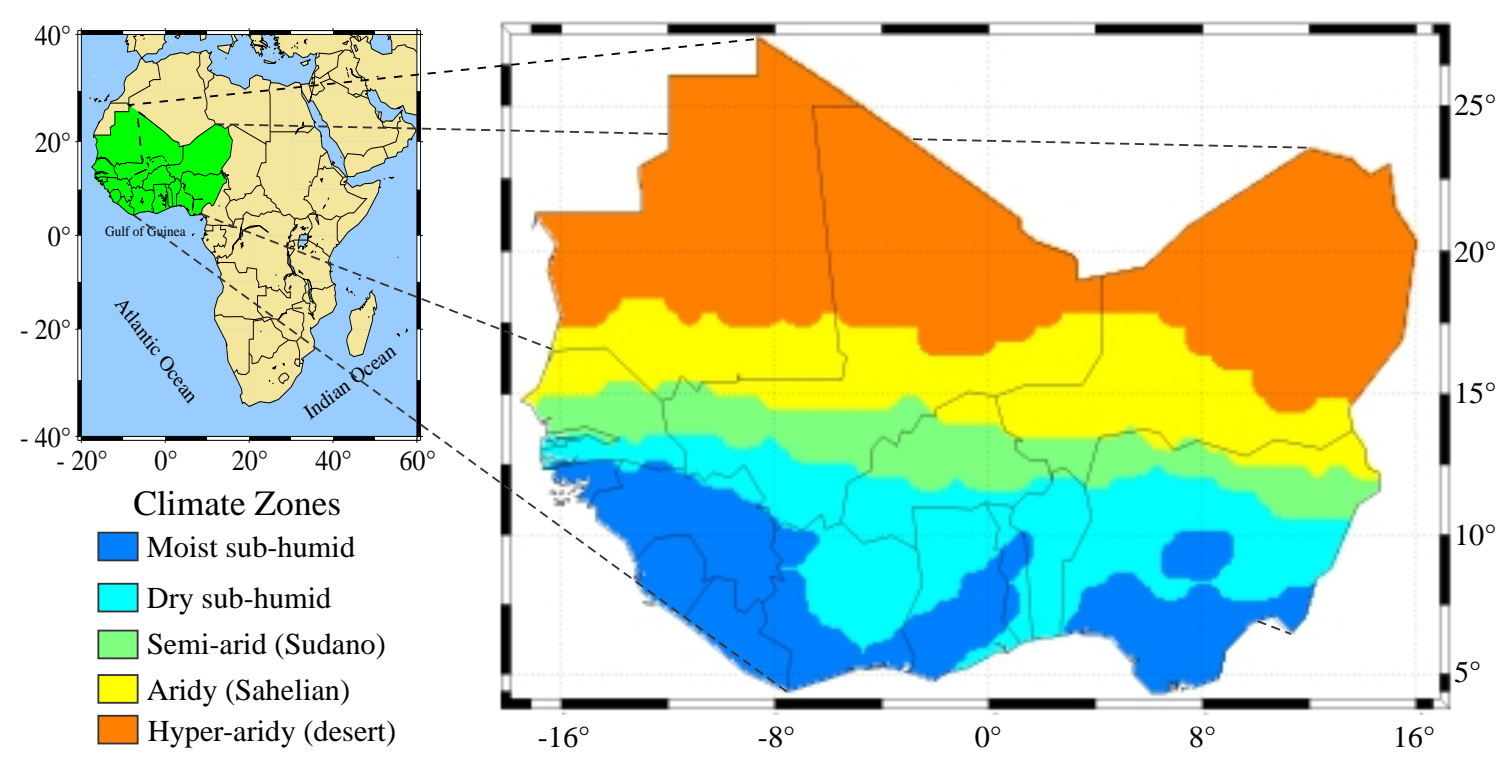

Figure 1: The study area domain in West Africa as well as its sub-climatic zones as proposed in Section 2.2.

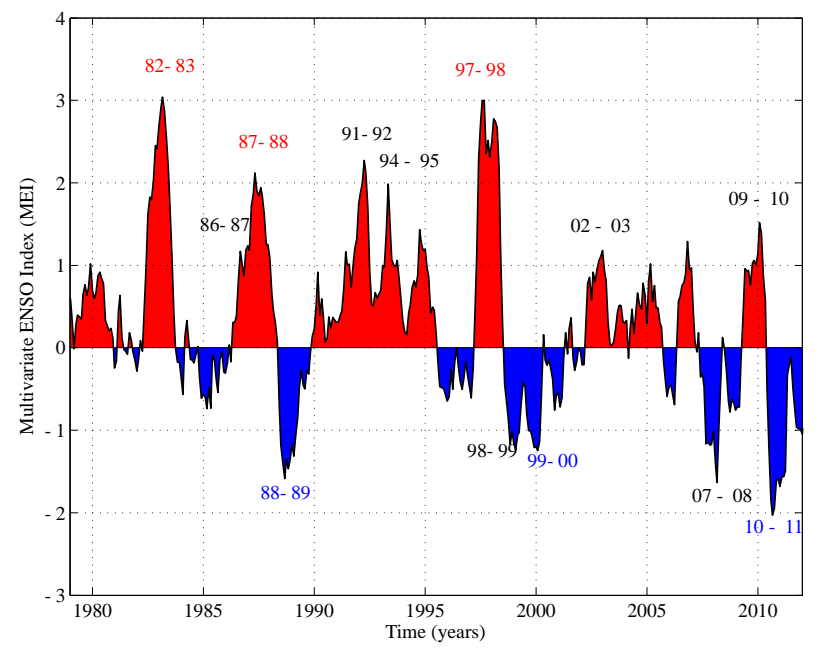

Figure 2: Multivariate ENSO Index (MEI) where El Niño (positive phase) is presented in red and La Niña (negative phase) in blue. Numbers on the plot indicate El Niño/La Niña event years. Red and blue digits represent strong El Niño and La Niña events, respectively. Black digits show the moderate years for both events. 


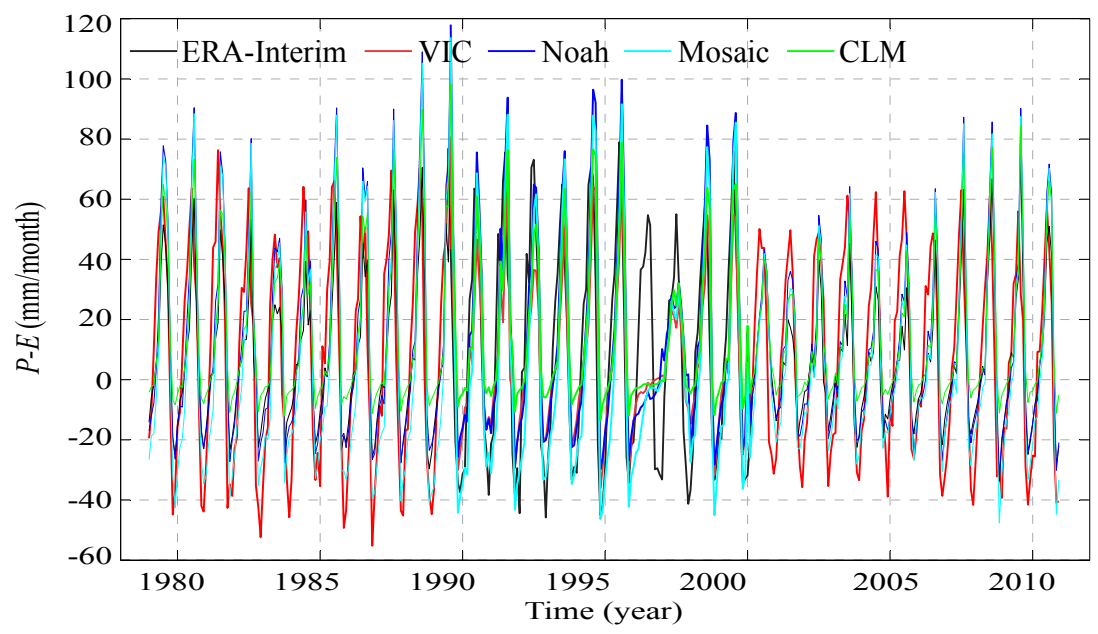

Figure 3: Spatially averaged time series of monthly net-precipitation estimates over West Africa, based on four GLDAS products (VIC, Noah, Mosaic and CLM) and ERA-Interim data from 1979 to 2010. While all datasets appear to be consistent, especially with regards to seasonal patterns, the GLDAS products present some inconsistencies around 1997.

a) Monthly standardized rainfall (West Africa)

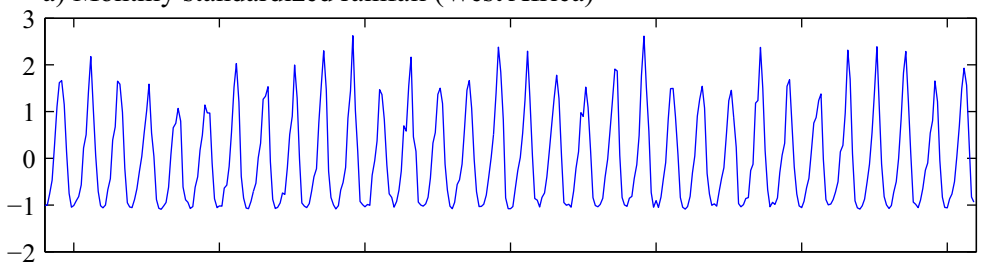

b) Wavelet power spectrum

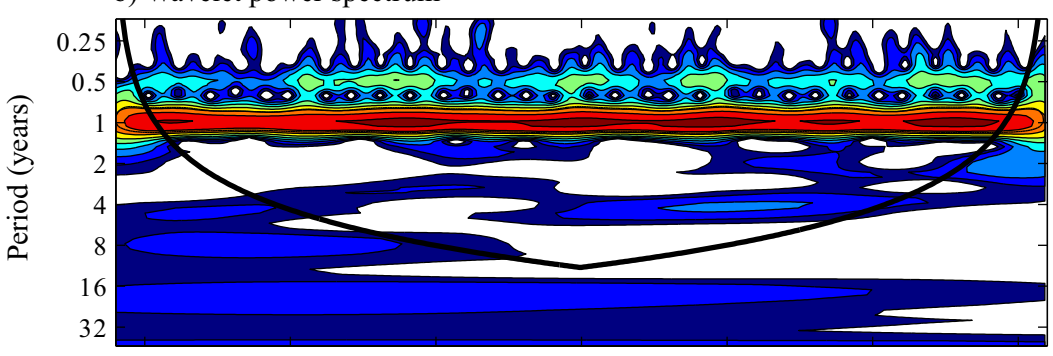

c) Global wavelet spectrum

d) 1 year scale averaged power
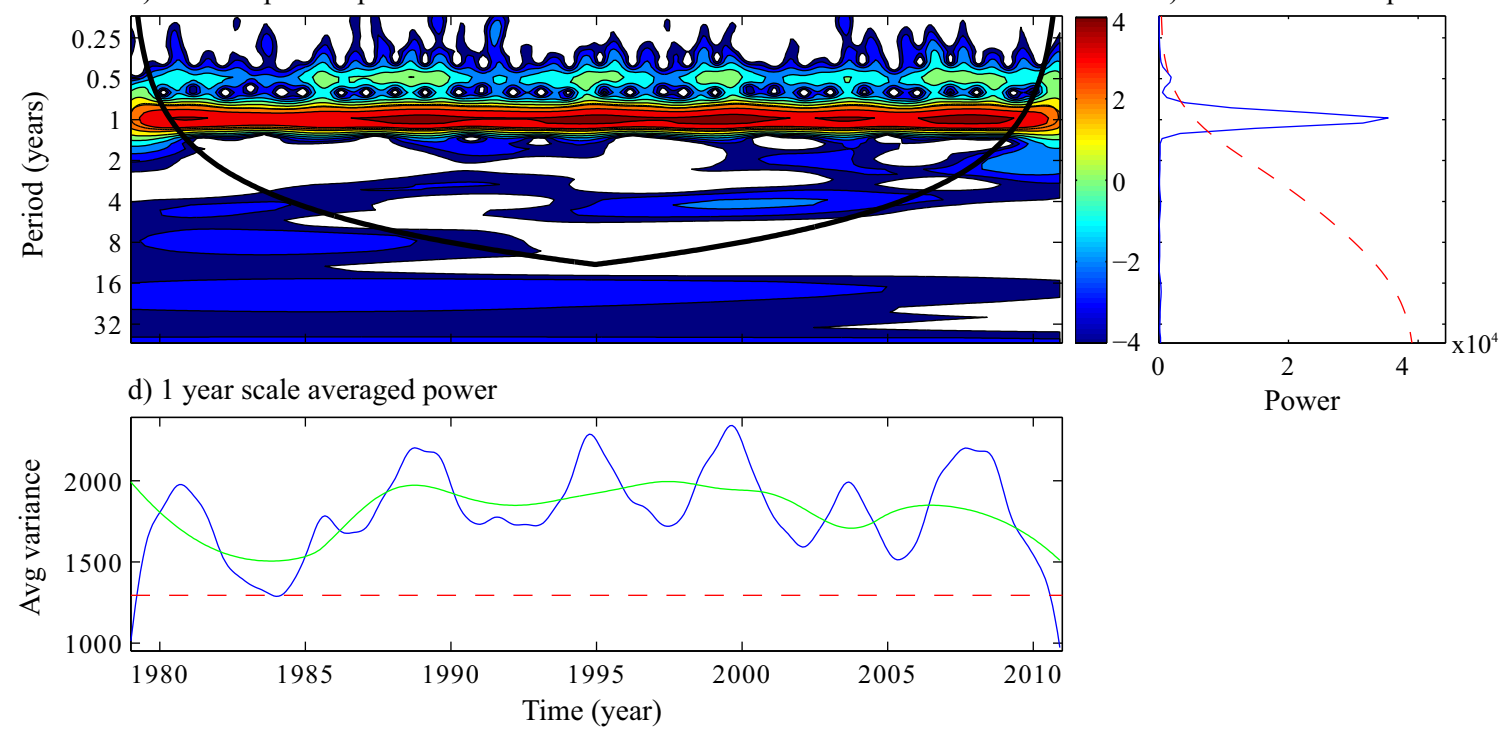

Figure 4: Wavelet transform of areal averaged standardized rainfall over West Africa. a) Is the standardized time series of rainfall, b) is the wavelet power transform, where the thick black arc defines the cone of influence which indicates the boundary beyond which the spectral information are vulnerable to distortions due to edge effects (Torrence and Compo, 1998; Grinsted et al., 2004), c) is the global wavelet spectrum for the WPS, and d) is the averaged power at the annual scale (blue), where the dashed red line represents the significance at a 95\% confidence level; and green, the long term trend. The rainfall WPS show a modest recovery from the dry spells in the 1980s. 
a) Monthly standardized P-E (West Africa)

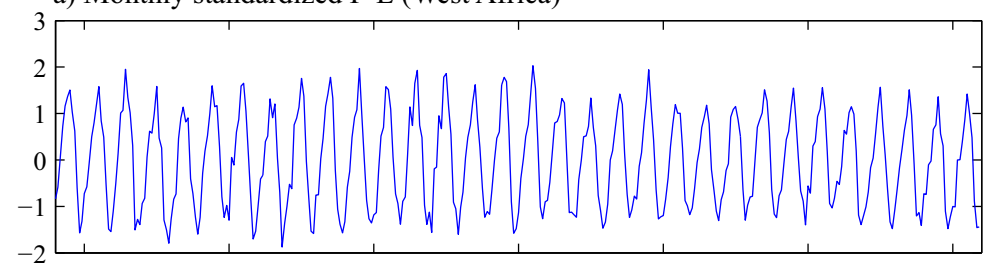

b) Wavelet power spectrum

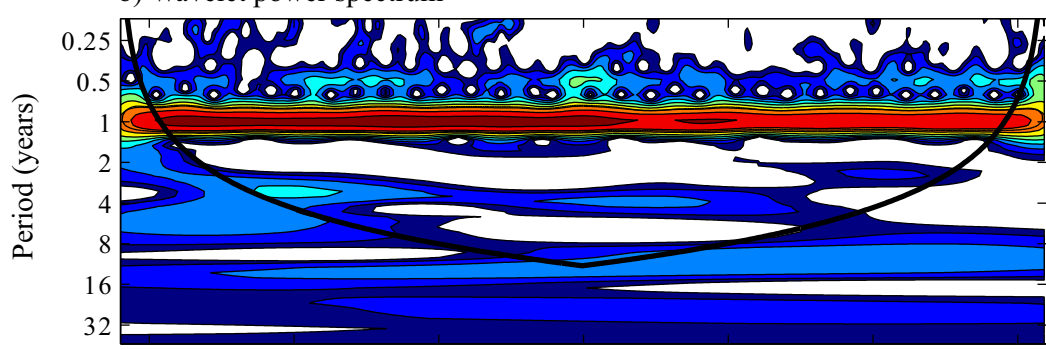

d) 1 year scale averaged power

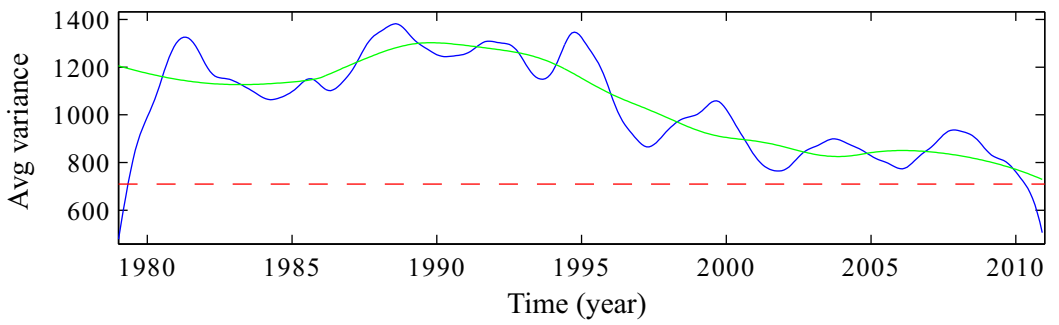

c) Global wavelet spectrum

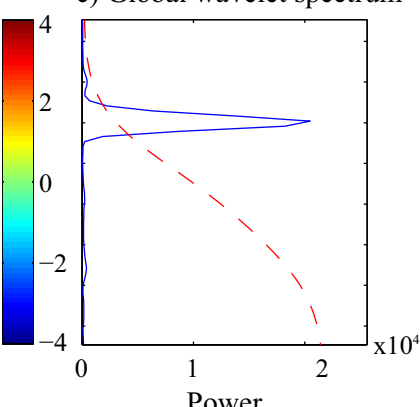

Power

Figure 5: Wavelet transform of areal averaged standardized net-precipitation $(P-E)$ over West Africa. a) is the standardized time series of $P-E, \mathrm{~b}$ ) is the wavelet power transform, which the thick black arc defines the cone of influence, c) is the global wavelet spectrum for the WPS, and d) is the averaged power at the annual scale (blue), which the dashed red line shows the significance at a $95 \%$ confidence level, while the green is the long term trend. In contrast to rainfall, net precipitation WPS show decreasing trend between 1979 to 2010.
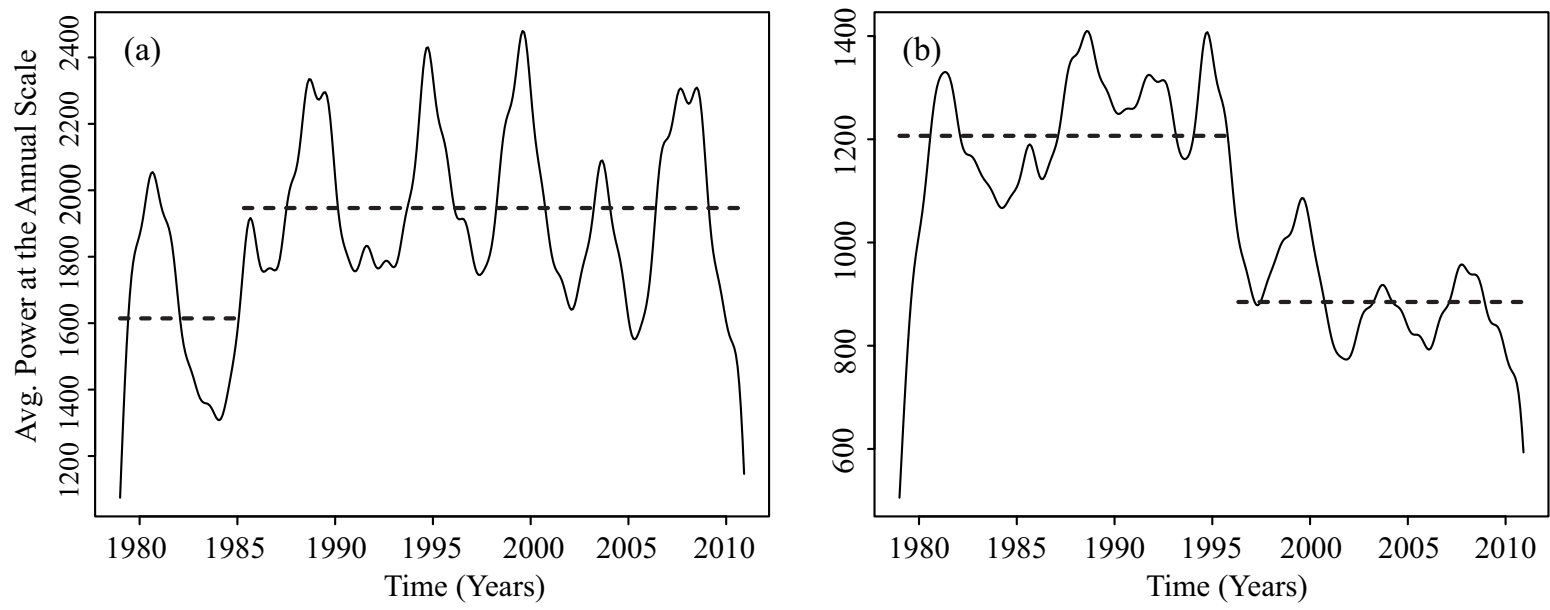

Figure 6: Step change analysis for the averaged power at the 1-year scale for rainfall (a) and $P-E$ (b). Rainfall over WA experienced a positive change in both mean and variance at epochs 1985.25 and 1996.25 respectively. Note that the dashed lines indicate the different means as indicated by the analysis. 

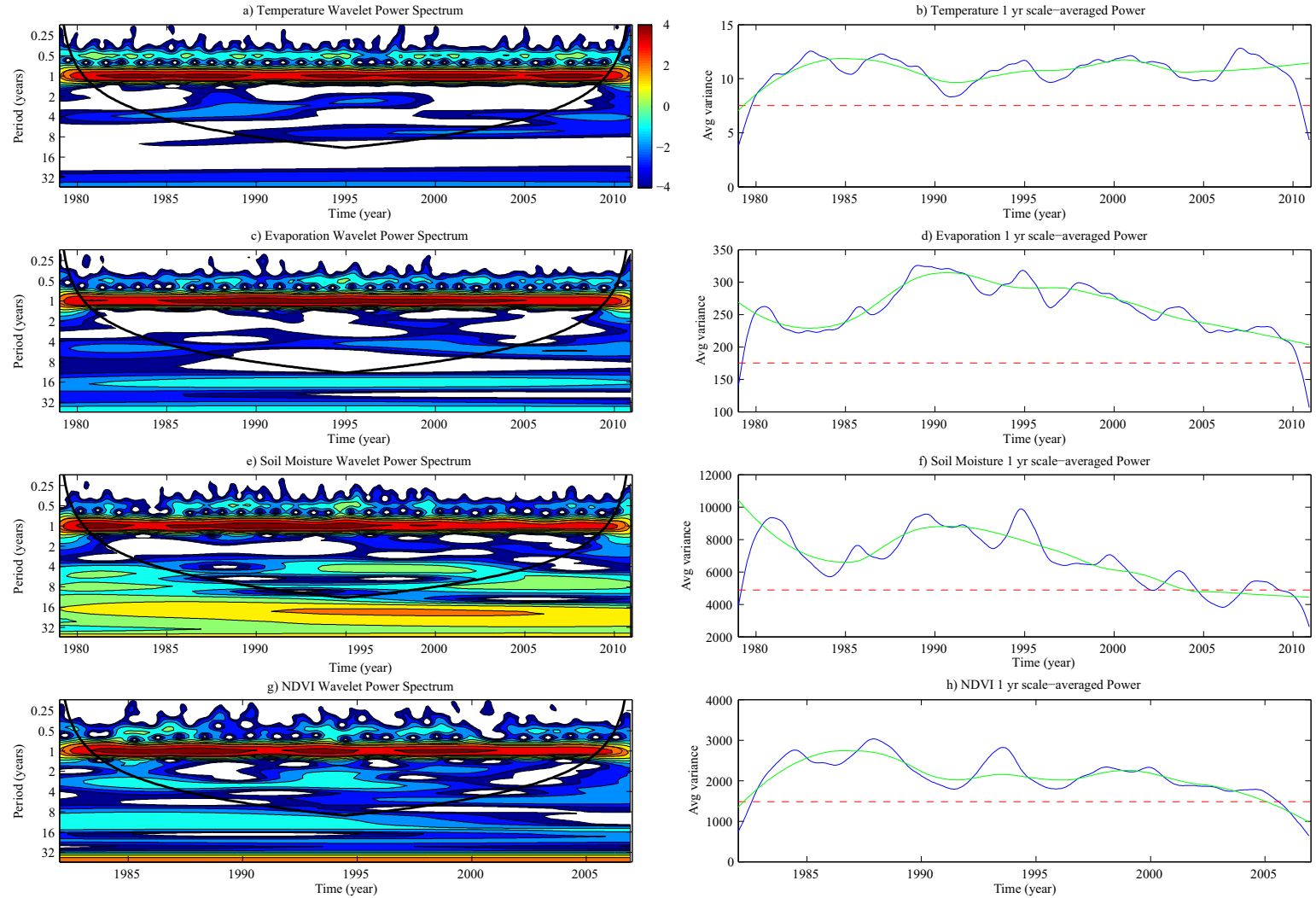

Figure 7: The WPS for (a) temperature, (c) evaporation, (e) soil moisture and (g) NDVI and their averaged power at the annual time scale in (b), (d), (f), and (h), respectively. Evaporation, soil moisture and NDVI all present decreasing trends in WPS as shown in the average 1-year scaled power. 

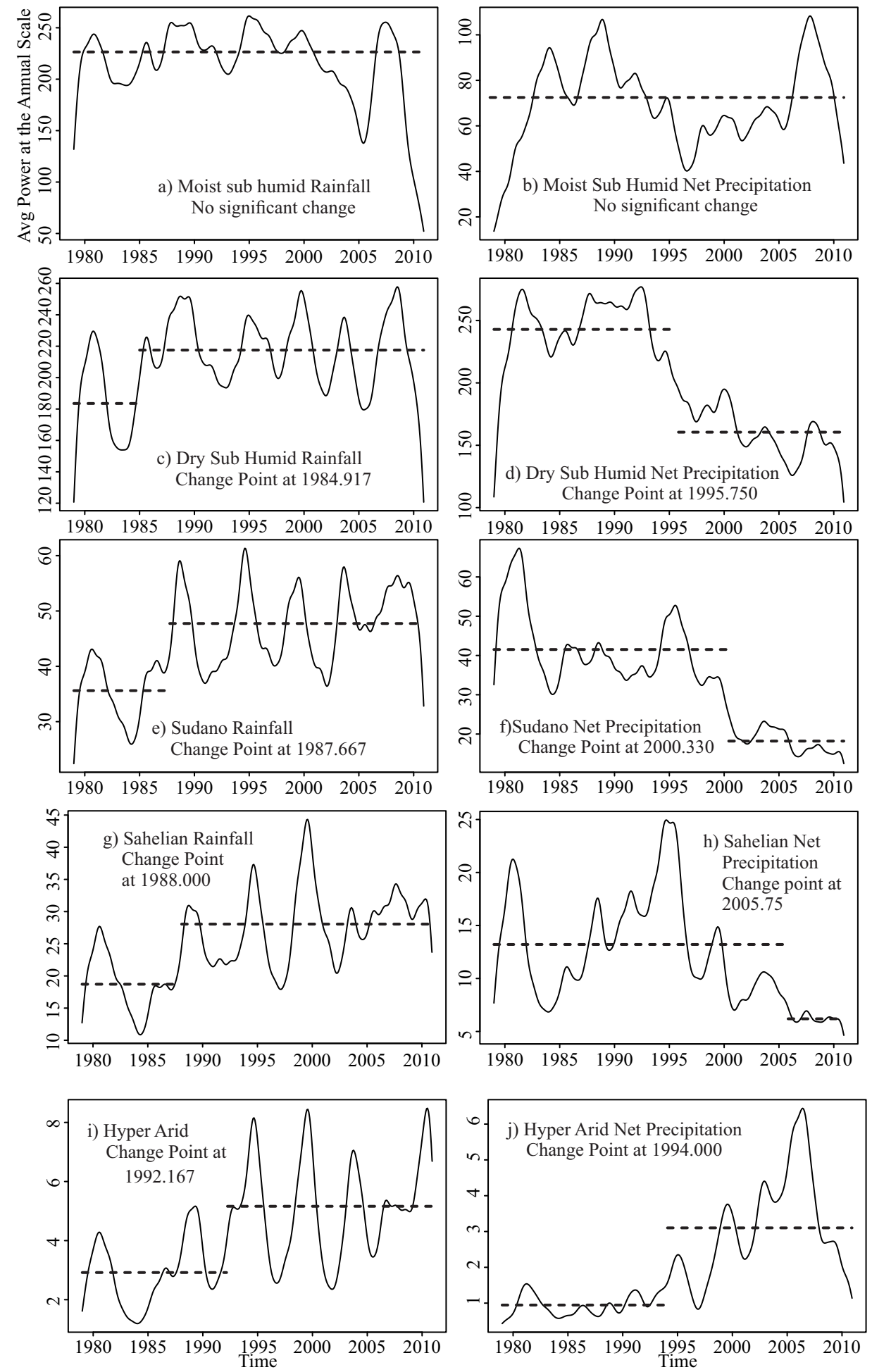

Figure 8: 1-year scale-averaged power of rainfall and net-precipitation for the different sub-climatic zones in WA (see Figure 1), i.e., a) Moist sub-humid, b) Dry sub-humid, c) Sudano, d) Sahelian, and e) Hyper-arid. Step change analysis showed that for b) to d), rainfall in the 1980s had lower means and higher means from the 1990s. On the other hand, mean power for net precipitation was higher in the first half of the period of study and lower in the other. The moist sub-humid zone (a), however, shows a no significant change in mean. 

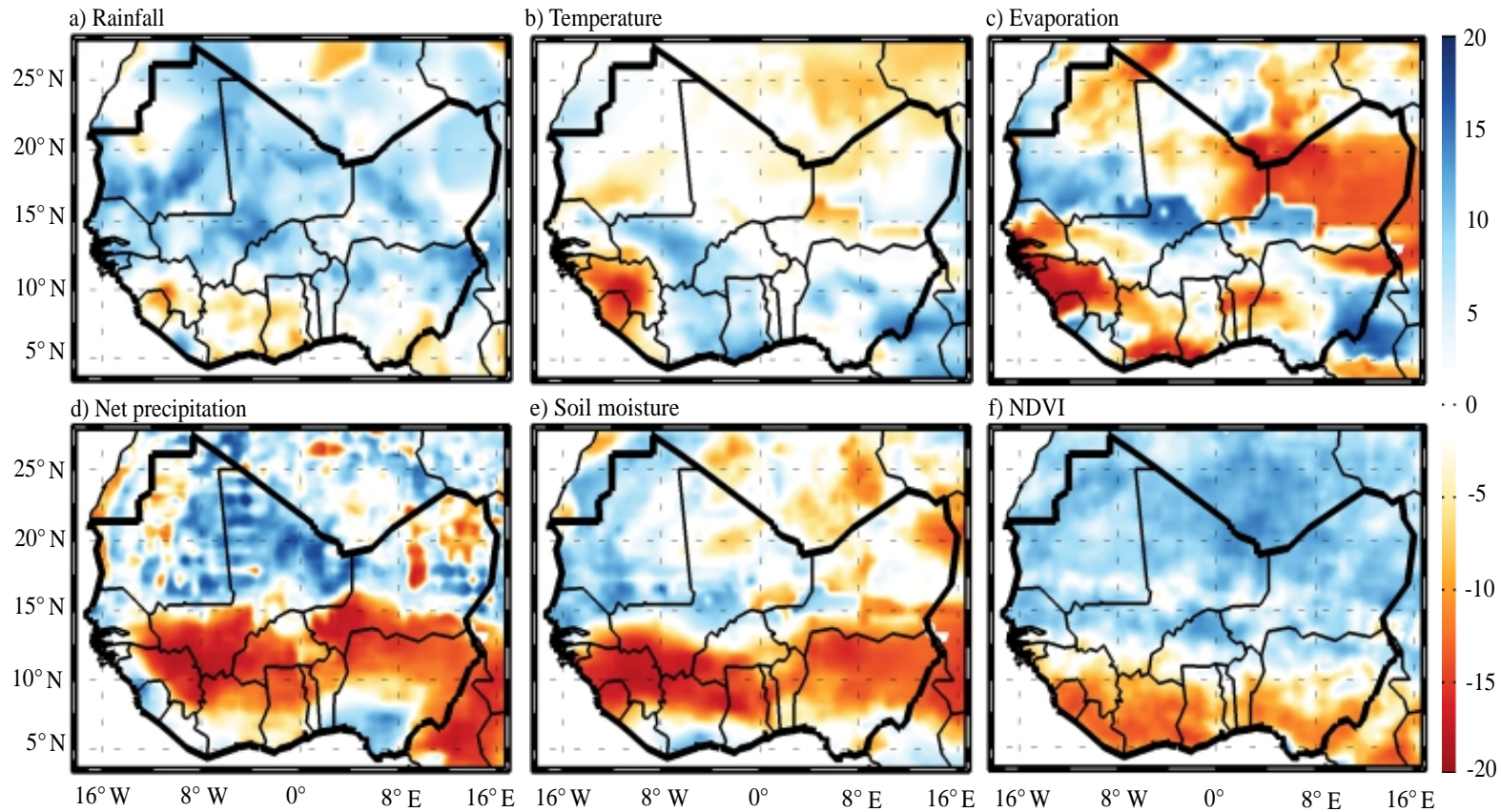

Figure 9: Spatial wave power spectrum trends at the annual timescale over West Africa, where a) Rainfall, b) Temperature, c) Evaporation, d) $P-E$ (Net-precipitation), e) Soil moisture, and f) NDVI.

a) Rainfall
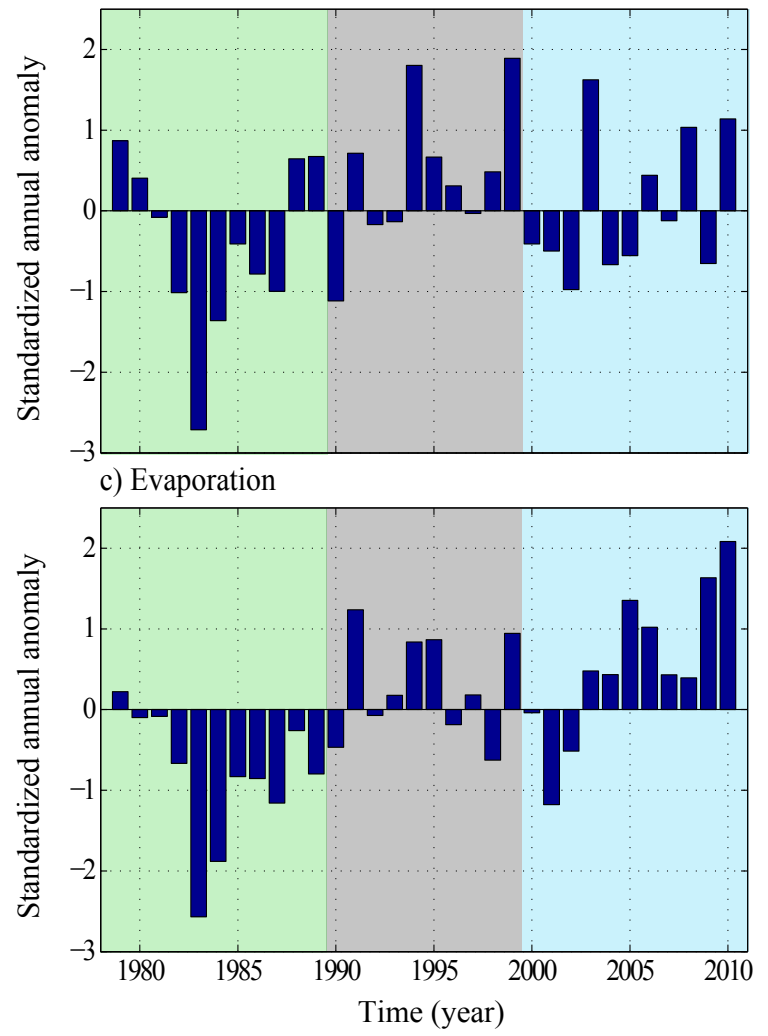

b) Net precipitation

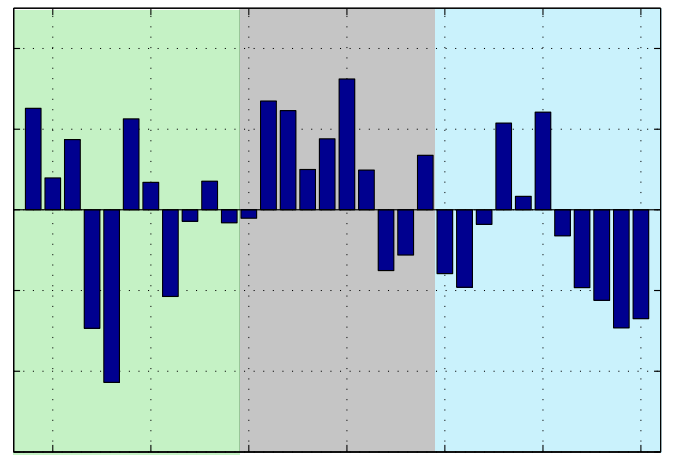

d) Temperature

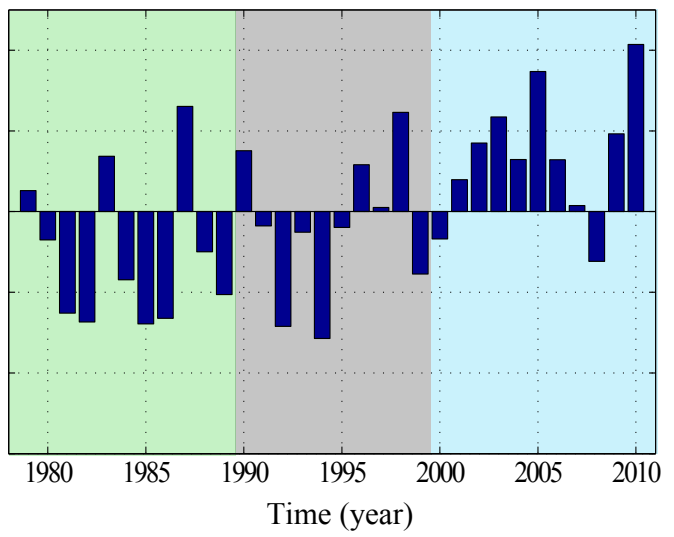

Figure 10: Deviations from mean annual: (a) Rainfall; (b) Net-precipitation; (c) Evaporation; (d) Temperature. The colour graduations show the different decades of interest. 
a) Rainfall/MEI

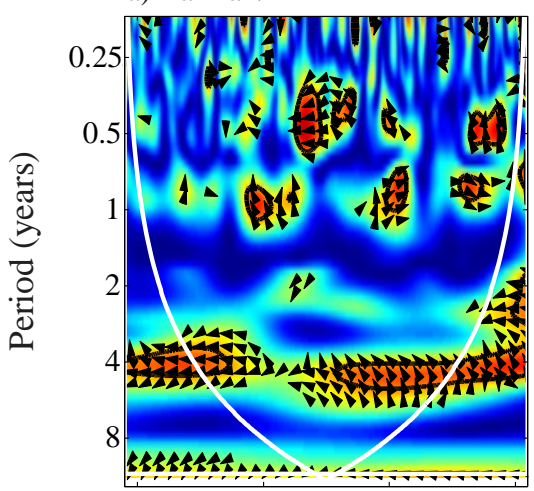

d) Net precipitation/Rainfall

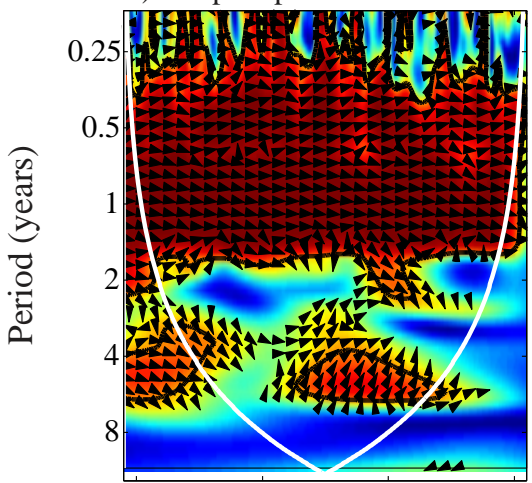

g) Evaporation/Rainfall

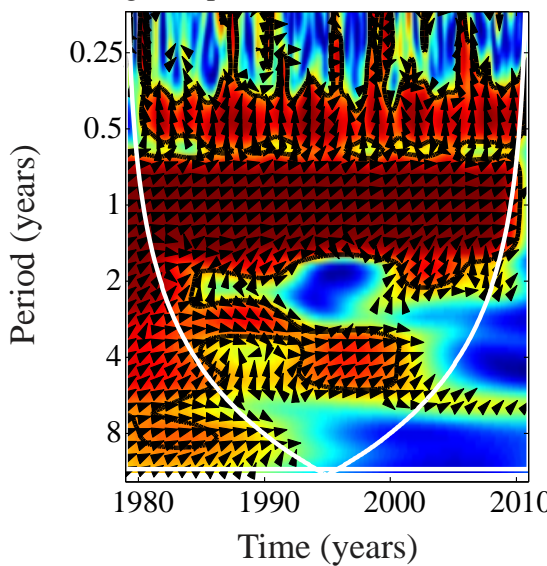

b) Net precipitation/MEI

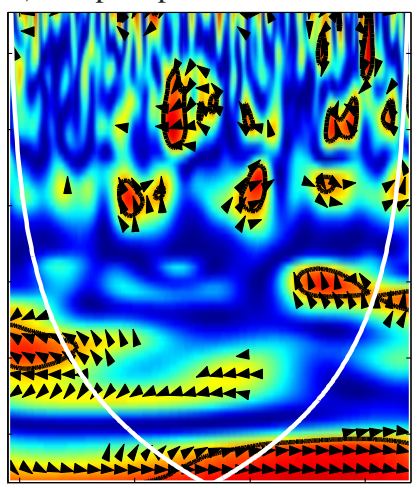

e) Net precipitation/Evaporation

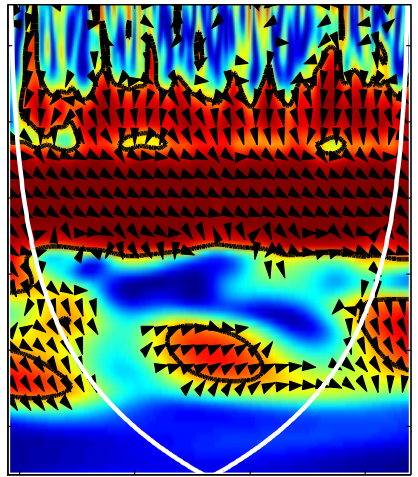

h) Temperature/Rainfall

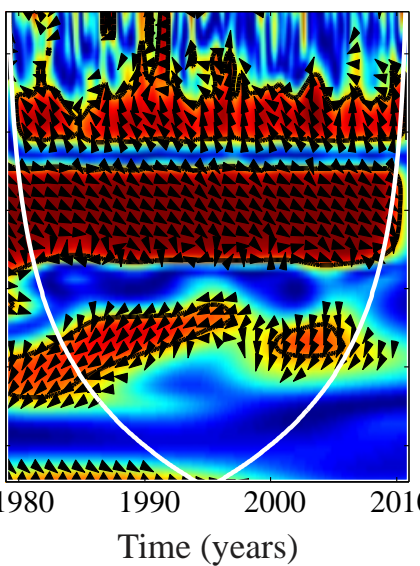

c) Evaporation/MEI

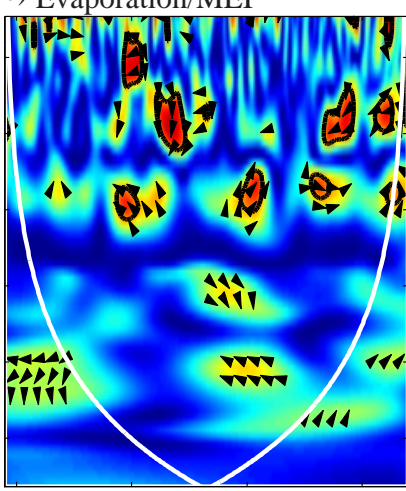

f) Net precipitation/Temperature

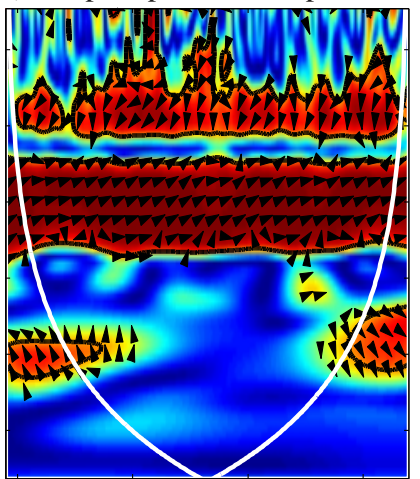

i) Temperature/Evaporation

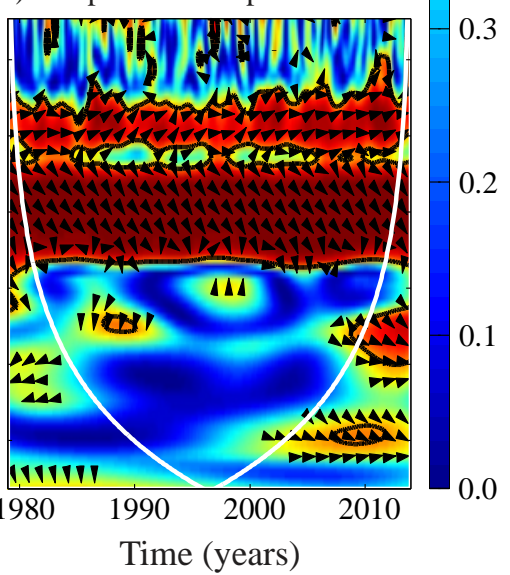

Figure 11: Wavelet coherency between: (a) Rainfall and MEI; (b) Net-precipitation $(P-E)$ and MEI; (c) Evaporation and MEI; (d) Net-precipitation and Rainfall; (e) Net-precipitation and Evaporation; (f) Net-precipitation and Temperature; (g) Evaporation and Rainfall; (h) Temperature and Rainfall; and (i) Temperature and Evaporation. The areas outside the COI (white solid line) show regions where edge effects might cause some distortion in the time frequency spectrum while the thick black contours designate the $95 \%$ confidence level against red noise. The arrows show the phase difference between the signals, for 2 series, X and Y (Grinsted et al., 2004): a right pointing arrow indicates an in-phase relationship; left, anti-phase; down, X leads Y by $90^{\circ}$ and up, Y leads X by $90^{\circ}$. Net-precipitation exhibits a strong relationship with rainfall, evapotranspiration and NDVI but not so much with temperature. 
Table 1: Mean power changes between 1979-1995 and 1996-2010. dPow is the mean change in the signal's power spectrum and pPow is the proportion of power contributed by the sub-climatic zone. The acronym MSH stands for moist sub-humid zone, DSH stands for dry sub-humid, SUD stands for Sudano, SAH stands for the Sahelian, HyA stands for Sahara desert, and WA stands for the entire West African region.

\begin{tabular}{lrrrrrrrr}
\hline \hline \multirow{2}{*}{ Region } & \multicolumn{2}{c}{ precipitation } & \multicolumn{2}{c}{ Temperature } & \multicolumn{2}{c}{ Evaporation } & \multicolumn{2}{c}{$P-E$} \\
\cline { 2 - 9 } & dPow & \multicolumn{1}{c}{ pPow } & \multicolumn{1}{c}{ dPow } & pPow & \multicolumn{1}{c}{ dPow } & pPow & dPow & pPow \\
\hline MSH & $-12.56 \%$ & $42.97 \%$ & $-11.38 \%$ & $0.19 \%$ & $-31.35 \%$ & $0.17 \%$ & $-0.55 \%$ & $21.75 \%$ \\
DSH & $+2.69 \%$ & $42.22 \%$ & $+10.26 \%$ & $0.92 \%$ & $+4.36 \%$ & $12.58 \%$ & $-33.60 \%$ & $63.34 \%$ \\
SUD & $+17.22 \%$ & $8.88 \%$ & $+2.65 \%$ & $2.67 \%$ & $-0.80 \%$ & $46.48 \%$ & $-50.11 \%$ & $10.51 \%$ \\
SAH & $+34.16 \%$ & $5.08 \%$ & $+2.95 \%$ & $22.44 \%$ & $-7.14 \%$ & $39.81 \%$ & $-42.25 \%$ & $3.75 \%$ \\
HyA & $+48.08 \%$ & $0.85 \%$ & $+0.08 \%$ & $73.78 \%$ & $-52.17 \%$ & $0.96 \%$ & $+223.97 \%$ & $0.65 \%$ \\
\hline WA & $+4.05 \%$ & $100 \%$ & $+7.80 \%$ & $100 \%$ & $-8.09 \%$ & $100 \%$ & $-26.02 \%$ & $100 \%$ \\
\hline \hline
\end{tabular}

Table 2: Mean annual changes of $P-E$, rainfall, evaporation, and temperature with respect to the three decades (19791989, 1990-1999 and 2000-2010, labelled as 1, 2, and 3, respectively) within the period of study. Note that $\Delta_{(i, j)}$, with $i=2,3$ and $j=1,2$, is the difference between the average quantity observed in decade $i$ and decade $j$.

\begin{tabular}{lcrcr}
\hline \hline Differences & $P-E$ & Rainfall & $E$ & Temperature \\
\hline$\Delta_{(2,1)}$ & $+20.32 \%$ & $+7.03 \%$ & $+3.59 \%$ & $+0.04 \%$ \\
$\Delta_{(3,1)}$ & $-10.54 \%$ & $+3.74 \%$ & $+4.41 \%$ & $+0.14 \%$ \\
$\Delta_{(3,2)}$ & $-30.86 \%$ & $-3.29 \%$ & $+0.82 \%$ & $+0.10 \%$ \\
\hline \hline
\end{tabular}

